\title{
"Couldn't it be Birth to Five?": Parents' Perceptions of Early Intervention for their Children with Autism Spectrum Disorder
}

\author{
Hilary R. Bougher-Muckian
}

Follow this and additional works at: https://researchrepository.wvu.edu/etd

\section{Recommended Citation}

Bougher-Muckian, Hilary R., "'Couldn't it be Birth to Five?": Parents' Perceptions of Early Intervention for their Children with Autism Spectrum Disorder" (2018). Graduate Theses, Dissertations, and Problem Reports. 7163.

https://researchrepository.wvu.edu/etd/7163

This Dissertation is protected by copyright and/or related rights. It has been brought to you by the The Research Repository @ WVU with permission from the rights-holder(s). You are free to use this Dissertation in any way that is permitted by the copyright and related rights legislation that applies to your use. For other uses you must obtain permission from the rights-holder(s) directly, unless additional rights are indicated by a Creative Commons license in the record and/ or on the work itself. This Dissertation has been accepted for inclusion in WVU Graduate Theses, Dissertations, and Problem Reports collection by an authorized administrator of The Research Repository @ WVU.

For more information, please contact researchrepository@mail.wvu.edu. 
“Couldn't it be Birth to Five?": Parents' Perceptions of Early Intervention for their Children with Autism Spectrum Disorder

Hilary R. Bougher-Muckian

Dissertation submitted to the College of Education and Human Services

at West Virginia University

in partial fulfillment of the requirements for the degree of

\section{Doctorate of Philosophy}

in

Interdisciplinary Education

with an emphasis in Human Development and Family Studies

Amy Root, Ph.D., Committee Chairperson

Jessica Troilo, Ph.D., Committee Chairperson

Kim K. Floyd, Ph.D., Committee Member

Michael Mayton, Ph.D., Committee Member

Melissa Sherfinski, Ph. D., Committee Member

Department of Learning Sciences and Human Development

Morgantown, West Virginia

2018

Keywords: Early intervention, autism, parenting, perceptions, grounded theory

(C) 2018 Hilary R. Bougher-Muckian 


\section{Abstract \\ “Couldn't it be Birth to Five?": Parents' Perceptions of Early Intervention for their Children with Autism Spectrum Disorder}

\section{by Hilary R. Bougher-Muckian}

The purpose of this Grounded Theory study was to understand parents of children with autism's perceptions of early intervention involvement, satisfaction, transition into and out of EI, and goals for their children's development. Twenty parents participated in initial interviews and 13 parents participated in follow-up interviews. Data were analyzed and a theory was generated to describe parents' experiences. Parents described their experiences and goals for their children in three stages: before, during, and after EI. In each of these stages, social and language/communication were a primary focus of parents' goals for their children's development. Prior to EI, parents expressed a high level of frustration with the referral process into EI. Parental agency was key in gaining access to EI services. During EI, parents described high levels of satisfaction, involvement and collaboration with service providers. After EI, parents again described high levels of frustration with access to services in the public school setting, with several parents having to seek private therapy. Parental selfeducation and the community of parents of children with autism were critical in helping parents gain access to services for their children. These findings highlight a need for more identification programs prior to EI and support programs for parents after aging out of EI. 


\section{Dedication}

For my daughter, Sophia Louise, and our soon to be son, Aidan Michael 


\section{Acknowledgements}

I would like to thank my family. Thank you for your unwavering support throughout my doctoral degree. Thank you for always believing in me and providing all of the words of encouragement over the years.

I would also like to thank my committee members: Drs. Amy Root, Jessica Troilo, Kimberly Floyd, Michael Mayton, and Melissa Sherfinski. Thank you for sharing your wisdom and expertise with me. Having such a knowledgeable, interdisciplinary committee has been incredibly helpful to me throughout this process.

To my advisor and one of my committee chairs, Amy Root, thank you for everything you have done for me throughout the years. We have worked together since my undergraduate. Your wisdom and untiring belief in me as a researcher has been invaluable to me. I cannot thank you enough and I genuinely look forward to our collaborations to come!

To Jessica Troilo, co-chair of my committee. Thank you for all of your support and guidance. I could not have finished this dissertation without your expert guidance on interviewing and qualitative analysis.

This project was funded by a graduate student research award at West Virginia University, the Robert E. Stitzel Graduate Student Research Award. I would like to show my sincerest appreciation to the the funders of this award.

Finally, I would like to thank the parents who participated in this study. Thank you for sharing your personal experiences with early intervention with me. Without your participation, this study would not be possible. 


\section{Table of Contents}

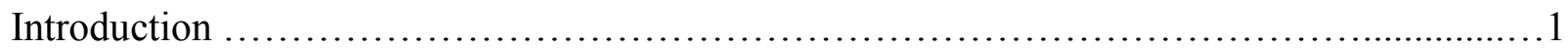

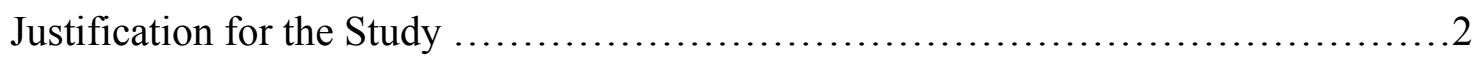

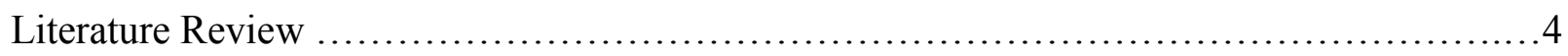

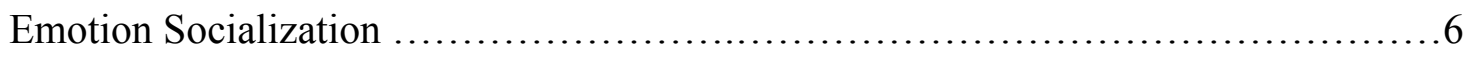

Emotion Socialization and Typically Developing Samples.................6

Emotional Challenges Related to ASD ..................................8

Emotion Socialization and Children with ASD ............................ 10

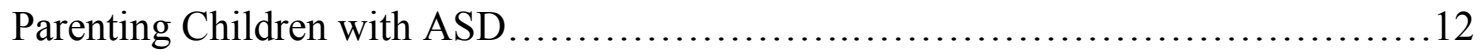

Parenting and Interventions............................................ 14

Parent-Implemented and family-focused interventions...................... 14

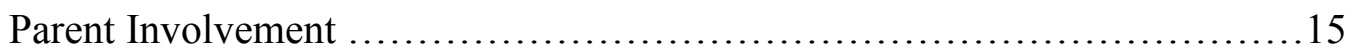

Parents' Perceptions of Interventions....................................15

Theoretical Sensitivity.................................................. 18

Researcher Positionality...............................................20

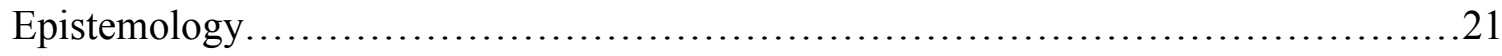

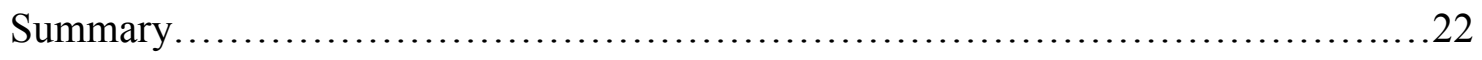

Research Questions.....................................................24

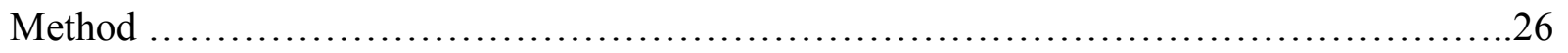

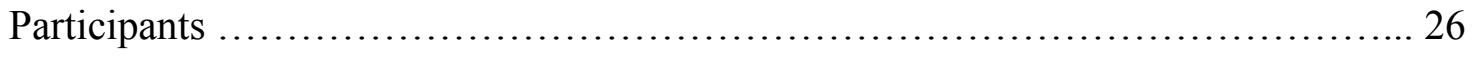

Parent Demographics.............................................26

Child Demographics...............................................27

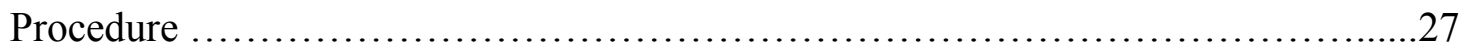




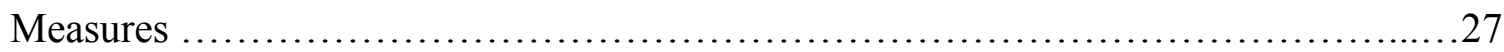

Demographic Questionnaire ..........................................28

Open-ended Interviews............................................... 28

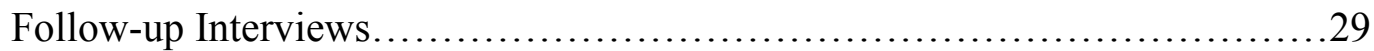

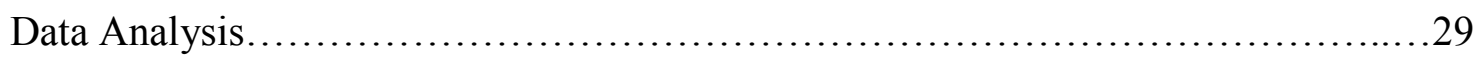

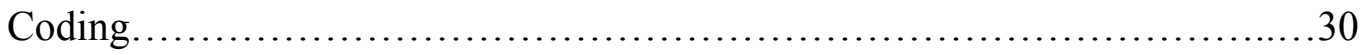

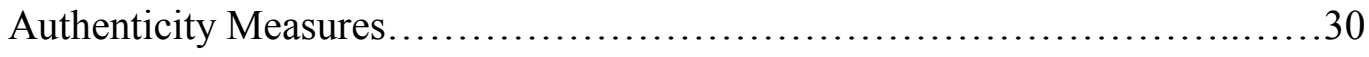

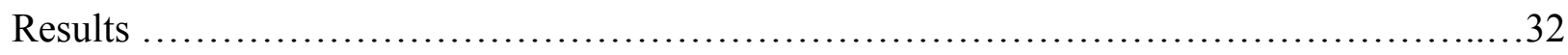

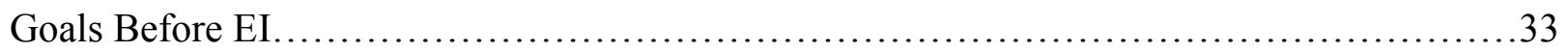

Frustration Surrounding Initial Referral Professionals for not referring .....................33

Frustration with Professionals for not referring....................................34

Parent Agency in Starting EI.................................................. 35

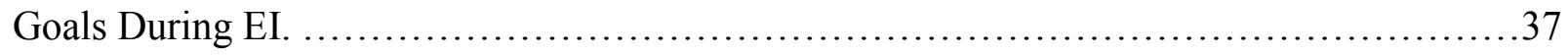

Collaboration Between Service Providers and Family Members...............................39

Family Involvement and Skilled Service Providers.................................39

Trust Between Service Providers and Parents....................................41

Child Progress as a Result of Collaboration and Skilled Service Providers.............42

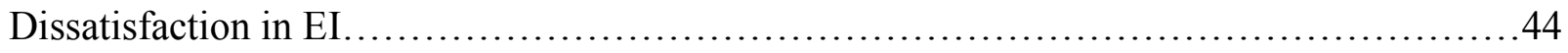

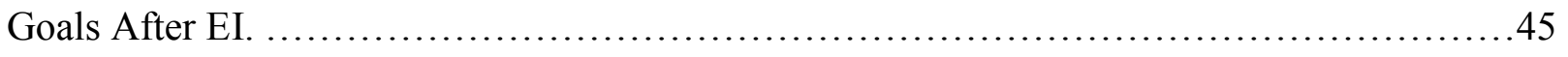

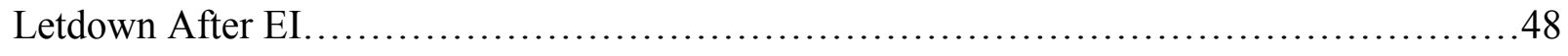

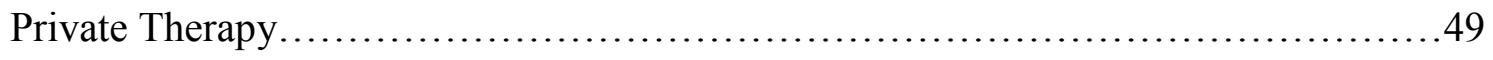

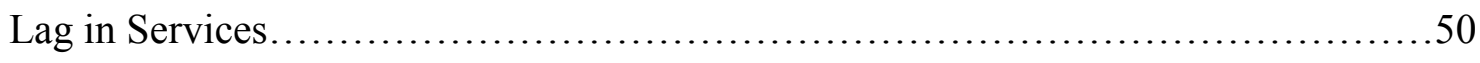

Reliance on Self-Education and Parent Community ................................53 


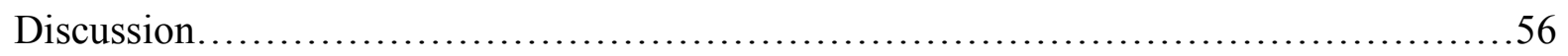

Theoretical Model and Propositions..........................................56

Parental Involvement and Satisfaction......................................58

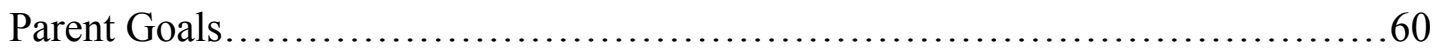

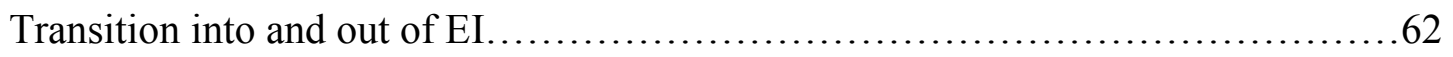

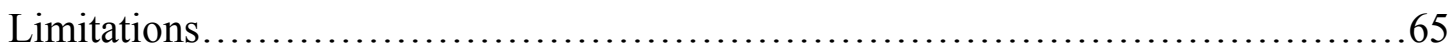

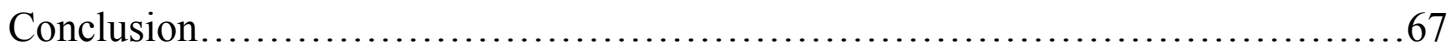

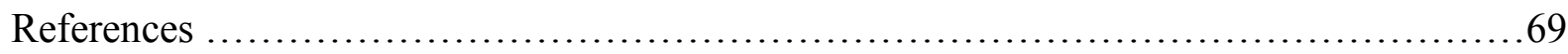




\section{List of Tables}

Table 1 - Participant demographic characteristics.................................... 80 


\section{List of Figures}

Figure 1 - Theoretical Model of Parents of Children with ASD's Perceptions of EI .......81 


\section{List of Appendices}

Appendix A - Demographic Questionnaire ......................................82

Appendix B -Interview Questions........................................... 87

Appendix C - Description of Stage Model........................................89

Appendix D - Before Early Intervention: Frustration with the Initial Referral.............90

Appendix E - During Early Intervention: Collaboration Between Service Providers and

Family Members........................................................91

Appendix F - Letdown After Early Intervention................................ 92

Appendix G - Parent Goals .................................................93 


\section{Chapter I}

\section{Introduction}

Early childhood is a critical period for forming emotional competence. One way children develop emotional competence through the process of emotion socialization (Denham, Bassett, \& Wyatt, 2007; Eisenberg, Cumberland, \& Spinrad, 1998). There are several agents involved in this process of emotion socialization; however, the family, and, more specifically, parents are often noted as the most influential and pervasive source of emotion socialization, particularly during infancy and childhood (Collins, Maccoby, Steinberg, Hetherington, \& Bornstein, 2000; Denham et al., 2007). Parents' supportive emotion socialization practices have been linked to better emotion regulatory skills (Cole, Dennis, Smith-Simon, \& Cohen, 2009; Eisenberg et al., 2003; Garner et al., 2008), increased empathy and perspective-taking skills (Taylor, Eisenberg, Spinrad, Eggum, \& Sulik, 2013), increased prosocial behavior (Brownell et al., 2013; Denham et al., 2007; Gross et al., 2015; Taylor et al., 2013) and socially appropriate displays of negative emotion (Brownell et al., 2013; Garner et al., 2008), while non-supportive emotion socialization practices have been found to be associated with higher levels of aggression and socially inappropriate behavior (Jones, Eisenberg, Fabes, \& MacKinnon, 2002; Leerkes, Blankson, \& O’Brien, 2009). Fortunately, interventions may be effective at teaching parents to use supportive emotion socialization practices (Havinghurst, Wilson, Harley, Prior, \& Kehoe, 2010).

Understanding the process of emotion socialization may be even more critical for children with autism spectrum disorder (ASD), given that studies indicate that many children with ASD struggle with skills related to emotional competence such as empathy and perspectivetaking, theory of mind, emotion regulation, and emotional understanding (Pouw, Rieffe, Oosterveid, Huskens, \& Stockmann, 2013; Samson et al., 2014; Samson, Hardan, Podell, 
Phillips, \& Gross, 2015; Tanaka et al., 2012). There is some evidence that parent-implemented interventions are effective tools to promote emotional competence in children with ASD (Mahoney \& Perales, 2003). Interventions for infants and young children with special needs tend to be most effective when they are family-centered (i.e., include parents in the planning and implementation phases, with goals focused on family needs; Dempsey \& Keen, 2008; Dunst, Hamby, \& Brookfield, 2007; McConachie \& Diggle, 2006). Within early intervention (EI), research suggests that parents of children with ASD may have higher levels of dissatisfaction than parents of children in other disability categories, with parents citing a lack of individualization and specification for children with ASD as their primary complaint (Coogle, Guerette, \& Hanline, 2013). Dissatisfaction with EI may lead to lower levels of involvement, and, ultimately, influence children with ASD, and their families, to have less positive experiences and outcomes (Bougher-Muckian, Coogle, Floyd, \& Root, in press).

\section{Justification for the Study}

The number of children diagnosed with ASD is currently one in 68 , with a $57 \%$ increase in diagnosis in the past 10 years (Centers for Disease Control, 2014). The primary delays for individuals with ASD, and those included in criteria for diagnosis, include social delays, communication delays, restricted interests and/or repetitive behavior, and sensory processing issues (Samson et al., 2014). In addition to the core areas, research indicates that children with ASD may also struggle in areas related to emotional competence including, but not limited to, empathy and perspective-taking, theory of mind, emotion regulation, and emotional understanding (Pouw et al., 2013; Samson et al., 2014; Samson et al., 2015; Tanaka et al., 2012). Some researchers have made a connection between the behavioral issues, which are often present in children with ASD, and delays in emotional regulation and understanding, noting that high 
levels of emotional dysregulation and low levels of emotional understanding are likely to result in higher levels of conflict with peers and higher engagement in aggressive behavior (BaronCohen, Golan, \& Ashwin, 2009; Pouw et al., 2013).

Fortunately, interventions are often effective in improving the emotional competence of children with ASD (Mahoney \& Perales, 2003; Williams et al., 2012). Family-centered and relationship focused interventions are most effective, and there is some research indicating that EI may be effective at improving both the emotion socialization practices of parents of children with ASD and their children's emotional competence (Mahoney \& Perales, 2003). Research indicates families of children with ASD have unique experiences with EI, with parents reporting higher levels of dissatisfaction and poorer outcomes than families of children in other disability categories (Bougher-Muckian et al., in press; Coogle et al., 2013). However, little is known about parents with ASD's experiences with EI, and how these perceptions of EI influence their participation. Thus, qualitative examination is necessary to better understand families of children with ASD's unique experiences with EI and their perceptions of satisfaction and involvement. This study utilized qualitative methods, specifically Grounded Theory Methods (GTM; Corbin \& Strauss, 1998; Glaser \& Strauss, 1967), to understand parents' goals for their children with ASD, satisfaction with past EI programs, and involvement in EI programs. 


\section{Chapter II}

\section{Literature Review}

Early childhood is a critical period for learning emotional regulation (Sheffield Morris et al., 2007). Emotion regulation can be defined as an individual's ability to modulate their emotions when it is "too much or too little for themselves," or to fit with expectations for social situations (Denham et al, 2007, pg. 615). In order to regulate, individuals may use a combination of behavioral, physical, and cognitive emotional regulatory strategies (Denham et al., 2007).

Emotional regulation is only one component in emotional competence, which also involves one's ability to understand emotions (i.e., knowledge about the various types of emotions, social appropriateness of emotional expressions, social causes, and how to read the emotions of others), and one's ability to effectively express emotions (Denham et al., 2007). Emotional competence has been linked to the development of social skills and overall social competence (Baker, Fenning, Crnic, 2011; Denham et al., 2003). For instance, one such study by Denham and colleagues (2003) found that children's emotional competence at age three predicted outcomes in social competence (as assessed by peer and teacher ratings) at age five. Conceptually, the link between children's emotional and social competence makes sense given that all three aspects of emotional competence, emotional regulation, emotional expression, and emotional understanding are critical elements of relationships throughout life. Among young children, these aspects of emotional competence often influence friendships, sociometric status, and prosocial behavior (Baker et al., 2011; Denham \& Kochanoff, 2002; Denham et al., 2007; Gross et al., 2015). In order for children to foster positive peer relationships and resolve conflicts, children must be able to understand the emotional perspectives of others (Baker et al., 2011; Denham \& Kochanoff, 2002). Within social contexts, particularly when dealing with 
young children, conflicts abound. When children interact with their peers, and conflicts occur, a complex set of actions occur in which children must first attempt to regulate their own emotional response before attempting to understand the emotional perspective of their peer and, ultimately, come to some form of conflict resolution. When children are highly dysregulated (i.e., have high levels of negative emotions and are unable to modulate these negative emotions to more appropriate and easily managed levels), they may be unable to calm themselves down enough to try to understand the perspective of their peers. Higher levels of dysregulated anger has been linked to increased engagement in aggressive behavior (Pouw et al., 2013).

Given the related nature of emotional and social competence, it is important to understand the process, and factors, that contribute to emotional competence. Emotion socialization is the process through which children learn to regulate, express and understand emotions (Denham et al., 2007; Eisenberg et al., 1998). Parents are one of the primary socializers in this process, with parents' emotion socialization practices being linked to children's short- and long-term socio-emotional outcomes (Collins et al., 2000; Denham et al., 2007). One of the ways in which parents socialize emotion is through their responses to their children's expressions of emotion. These emotional responses are often categorized into supportive reactions and nonsupportive reactions (Denham et al., 2007; Wong et al., 2009). Parents' supportive emotional responses have been linked to the most positive outcomes for children (Sheffield Morris et al., 2007). For instance, studies have linked supportive emotion socialization practices with increases in children's emotion regulatory skills (Cole, Dennis, Smith-Simon, \& Cohen, 2009; Eisenberg et al., 2003; Garner et al., 2008), empathy and perspective-taking skills (Taylor, Eisenberg, Spinrad, Eggum, \& Sulik, 2013), prosocial behavior (Brownell et al., 2013; Denham et al., 2007; 
Gross et al., 2015; Taylor et al., 2013) and socially appropriate displays of negative emotion (Brownell et al., 2013; Garner et al., 2008).

Interventions in emotion socialization may be an effective way to teach parents' positive, supportive emotional socialization practices, and, ultimately, improve child outcomes. Havinghurst and colleagues' (2010) study provides evidence that among typically developing samples, interventions in emotion socialization may increase both children's emotional competence and parents use of supportive emotion socialization practices. In this study, parents of preschool aged children were randomly assigned to treatment and control groups, with the treatment group receiving an intervention geared on teaching parents about emotion socialization and supportive emotion socialization practices. Post-intervention, parents utilized higher levels of supportive emotion socialization practices and fewer non-supportive practices. After the intervention, children in the treatment group had increased emotional understanding and decreased behavior problems.

Given the promising findings on emotion socialization interventions for parents of children who are typically developing, expanding these studies on intervention to parents of children with disabilities is a logical next step. Examining how parent intervention can improve emotional competence may be even more critical in children with ASD since children with ASD often struggle with issues related to emotional regulation and behavioral inhibition, and thus may benefit more from intervention in this area (Baurain \& Nader-Grosbois, 2013; Brown \& Conroy, 2011; Pouw et al., 2013; Samson et al., 2015; Tanaka et al., 2012).

\section{Emotion Socialization}

Emotion socialization and typically developing samples. Emotion socialization is the process through which children learn to regulate, express, and understand emotions. There are a 
number of socialization agents in this process, including, but not limited to, peers (e.g, Denham et al., 2007), siblings (Denham et al., 2007), and teachers (e.g., Denham, Bassett, \& Zinsser, 2012; Morris, Denham, Bassett, \& Curby, 2013); however, parents are arguably one of the earliest and most profound influences in emotion socialization (Collins et al., 2000; Denham et al., 2007). Modeling is one way in which parents socialize children in the development of emotional competence. Often unknowingly, through their behavior and emotional expressions, parents model emotional understanding, emotional regulation, and emotional expression to their children. Children often model the types of emotions their parents frequently express. Parents' persistent high levels of negative emotionality (i.e., anger, sadness, fear) have been linked to high levels of negative emotionality in children, while high levels of positive emotionality (e.g., happiness) have been linked to high levels of positive emotionality in children (Garner \& Estep, 2001). Parents also engage in emotional discourse (i.e., discussions about emotions) with their children. Maternal emotional discourse has been found to predict children's prosocial behavior and aggression (Brownell et al., 2013; Garner et al., 2008).

Another way parents socialize emotion is through the way they respond to their children's emotional expressions. These emotional responses are often described as supportive and non-supportive responses. Supportive responses are warm and sensitive responses, which promote future emotional expression and emotional regulation, and validate emotions (Denham \& Kochanoff, 2002; Denham et al., 2007). Non-supportive responses are punitive or dismissive reactions to children's emotions (Eisenberg \& Fabes, 1994; Denham et al., 2007; Denham \& Kochanoff, 2002). Supportive responses are associated with higher emotion regulatory ability (Cole et al., 2009; Eisenberg et al., 2003; Garner et al., 2008), empathy and perspective-taking (Taylor, Eisenberg, Spinrad, Eggum, \& Sulik, 2013), emotional understanding (Perlman, 
Camras, \& Pelphrey, 2008) and appropriate, non-aggressive displays of anger (Brownell et al., 2013; Leerkes et al., 2009; Garner et al., 2008), while non-supportive responses are associated with higher levels of aggression and socially inappropriate behavior (Jones et al., 2002; Leerkes et al., 2009).

Emotional challenges related to ASD. Given that many children with ASD often struggle with issues related to emotional dysregulation, the findings of the above studies on emotion socialization may have significant implications for the lives of children with ASD. Specifically, research indicates that children with ASD may experience significant challenges related to empathy and perspective-taking, theory of mind, emotion regulation, and emotional understanding (Pouw et al., 2013; Samson et al., 2014; Samson et al., 2015; Tanaka et al., 2012). Tanaka and colleagues (2012) examined potential differences in the emotional understanding of children, adolescents, and young adults with ASD. They found that, in comparison to the control group, the typically developing group, children with ASD had more difficulty with holistically recognizing emotion-related facial expressions and placing appropriate emotions with faces.

In a series of studies, Samson and colleagues $(2014 ; 2015)$ examined emotional dysregulation among children with ASD. Samson and colleagues (2015) utilized an emotion regulation task to determine how emotional reactivity and regulation differ for children and adolescents who are typically developing and children and adolescents with ASD. They found that children with ASD had significantly lower levels of cognitive reappraisal (i.e., cognitively reevaluating and adjusting emotional expressions) and significantly higher levels of emotional suppression than did children who were typically developing. During the task, when prompted to use cognitive reappraisal strategies, children with ASD had difficulty in utilizing these strategies. Samson and colleagues (2014) study also provides evidence indicating that children with ASD 
may struggle with emotional regulation. Utilizing parent-report survey data, they compared children with ASD with a typically developing control group and found that children with ASD had significantly higher levels of emotional dysregulation.

Children with ASD often have difficulty with behavioral inhibition, with some pointing to lower levels of emotional competence as a possible cause (Baron-Cohen et al., 2009). The results of Pouw and colleagues' (2013) study supports this connection. In their study, they examined the relationship between affective empathy (i.e., emotional contagion, or feeling an emotion when witnessing another person feel that emotion) and aggression in two groups: children who were typically developing and children with ASD (mean age of 11 years). They found that for children with ASD, affective empathy was positively related to reactive aggression, while, for children who were typically developing, affective empathy was negatively related to affective aggression. For children with ASD, observing other children in distress was related to higher levels of aggression. Similarly, in Samson and colleagues' (2014) study, children and adolescents with ASD were found to have significantly higher levels of emotional dysregulation than children who were typically developing, and dysregulation was reported to be related to higher rates of repetitive behavior. Taken together, these findings suggest that for children with ASD, issues related to both emotional regulation and emotional understanding could result in behavioral challenges, including higher levels of aggressive and repetitive behavior.

Importantly, though children with ASD may struggle in areas related to emotional competence, research suggests that interventions may be effective in improving the emotional competence of individuals with ASD. Williams and colleagues' (2012) study examined the effect of a video modeling intervention in emotional understanding on young children with ASD's 
emotional recognition. The intervention group showed significant gains related to recognition of anger.

Of particular relevance to the current study, parent-implemented interventions may also be effective at improving the emotional competence of children with ASD. In Mahoney and Perales (2003)' study, a relationship-focused intervention was implemented by parents to teach young children with ASD ages 3-5 at the time of intervention, emotional understanding and emotional regulation. Results indicate that the intervention was effective at improving parents' skills at teaching children emotion regulation. Post-intervention increases were also found related to children's empathy and emotion regulation.

Emotion socialization and children with ASD. Studies on emotion socialization in children with ASD are limited. The subject of emotion socialization for children with ASD has only begun to be examined. One of these studies, Bougher-Muckian, Root, Floyd, and Coogle (2016), examined the differences in the emotion socialization practices of parents of children who were typically developing and parents of children with ASD. Significant differences were found in parents' responses to anger; parents of children with ASD reported significantly higher levels of distress to children's displays of anger. It may be that some dimension of ASD is influencing parents' emotion socialization practices, resulting in significant differences in responses to anger between parents of children who are typically developing and parents of children with ASD. There is research suggesting that children with ASD may experience greater emotional dysresgulation related to anger (Baron-Cohen et al., 2009; Pouw et al., 2013). These differences in the peak levels of anger expressed between children with ASD and children who are typically developing may result in parents reporting higher levels of distress in relation to their children's expressions of anger. 
Parental attributions are another potential explanation for the differences in the emotion socialization practices of parents of children with ASD and parents of children who are typically developing. For instance, among a sample of young children (mean age of 7 years) with ASD, Bougher-Muckian, Root, Floyd, Coogle, and Hartman (2017) found that when ASD was less severe, parents were more likely to see their child's negative emotionality as alterable. Over time, having these views that their child's negative emotions are malleable may alter the way that parents respond to their children's emotions. Specifically, if parents see that their child can change their emotional expressions, they may be more likely to intervene and attempt to promote more positive and appropriate expressions in the future. It may be possible to intervene to adapt parents' attributions for their children's emotional expressions. Research in mental health (Green-Emrich \& Altmaier, 1991) and academic achievement among typically developing samples (Haynes, Perry, Stupnisky, \& Daniels, 2009; Haynes, Ruthig, Perry, Stupnisky, \& Hall, 2006) suggests that it is possible to train individuals to hold different attributions for behavior (i.e., attribution re-training), and ultimately these more positive attributions may result in more adaptive behavior and more positive outcomes; however, there have been no studies directly related to parenting, ASD, or emotion socialization. Additional research is needed to fully understand the complexity of how parents' attributions for children with ASD influence their emotion socialization practices, and what factors contribute to the formation of attributions.

Research among typically developing samples indicates that supportive emotion socialization practices result in more positive social and emotional outcomes for children (Jones et al., 2002; Leerkes et al., 2009). It would appear that there are differences in the emotion socialization practices of parents of children with ASD and parents of children who are typically developing, and that emotional attributions may be one possible explanation for these differences 
(Bougher-Muckian et al., 2017). It may be that interventions that include a dimension to promote supportive emotion socialization practices, and also involve some form of attribution re-training are most effective in improving emotion socialization practices and improving the socioemotional outcomes of children with ASD. There has been very little research on the perspectives and practices of parents of children with ASD in regards to emotion socialization, and, to date, there have been no intervention studies related to this subject.

\section{Parenting Children with ASD}

Qualitative research into parenting children with ASD is an emerging area of research. One qualitative study, Myers, Mackintosh, and Goin-Kochel (2009), examined how having a child with ASD (mean age of 8.5 years) impacted the lives of parents and families. They analyzed open-ended responses to survey questions using content analysis. Five overarching themes emerged: stress, child behavior, impact on the family, parent well-being, and social isolation. Themes across participant responses were then grouped into positive and negative aspects. For the child behavior theme, parents reported difficulty in dealing with their children's problem behaviors, but also noted that dealing with these issues gave them a better understanding of their child's needs related to their disability. In the theme for parent well-being, parents reported that raising a child with ASD had put a strain on their marriage, work-life, and emotional well-being; however, parents also reported positive effects on their well-being such as an increase in appreciation for life, increased patience, and greater tolerance and understanding for the plights of others. Parents reported sibling neglect and financial strain as negative effects of their child's disability to family functioning, but also noted positive affects on sibling relationships and increases in social support. Results of this study indicate that parenting a child with ASD can place significant stress and strain on the lives of parents and families, and increase 
feelings of social isolation, but many families seem to be able to overcome some of these challenges and, for many of the families in the study, having a child with a disability resulted in significant positive gains to family functioning, parent well-being, and social support.

A study by Woodgate, Ateah, and Secco (2011) also suggests that parenting a child with ASD may result in significant challenges related to parents' emotional well-being and family functioning. They utilized a hermeneutic phenomenological approach to examine parents' experiences, with interviews as the primary source of their data. They found themes in parents' experiences such as struggling to maintain both their own well-being and the well-being of their family, and struggling with feelings of social isolation. Parents reported that they felt that no one else understood their struggles in having a child with ASD. Parents also reported feeling like they needed to fight to advocate for their child's needs and rights, and to maintain their child's well-being and the overall functioning of their family.

In addition to feelings of social isolation, parents of children with ASD may also experience social stigmatization. Gill and Liamputtong (2011) found the theme of social stigmatization when they interviewed parents of children with Asperger's Syndrome. One of the primary themes that emerged from the data was that parents felt stigmatized by their school and community as a result of their child's diagnosis. Parents perceived higher levels of stigmatization toward their children with ASD than for children with other disabilities.

These qualitative studies on parenting a child with ASD suggest that parenting a child with ASD is complex. Parents report that having a child with ASD can result in high levels of stress, social isolation and stigmatization; however, parents also report that their child's disability has had positive impacts on their emotional well-being, social support, and overall family functioning (Gill \& Liamputtong, 2011; Myers et al., 2009; Woodgate et al., 2008). In relation to 
the current study, these complex experiences in parenting a child with ASD may influence parents' participation in EI programs, acting as potential reinforcements or barriers to participation. Given that there is research suggesting that EI programs are most effective when parents are highly involved (e.g., Dempsey \& Keen, 2008; Dunst et al., 2007; McConachie \& Diggle, 2006), it is critical to examine how parents' experiences may influence why parents do or not participate in interventions.

\section{Parenting and Interventions}

Parent-implemented and family-focused interventions. There are several agents involved in the process of emotion socialization, but, during the early childhood years, families, particularly parents, play a primary role (Sheffield Morris et al., 2007). Considering the significant role that parents play in the development of young children's emotional skills, it is critical that interventions in this area involve parents as intervention agents. In order for interventions to be effective, they should also be designed with parents' goals and needs in mind. Family-centered interventions are interventions that involve families in both the implementation and planning phases, with goals focusing on family needs (Dempsey \& Keen, 2008). The effectiveness of family-centered intervention is well supported. Family-centered practices are associated with positive outcomes for both families and children, and have been shown to be more effective than child-centered models for intervention (Bruder, 2000; Dempsey \& Keen, 2008; Dunst et al., 2007; Farrell, 2009; Talay-Ongan, 2001). Effective family-centered programs should utilize family goals and needs to formulate appropriate interventions (Dempsey \& Keen, 2008). In accordance with recent emphasis on family-centered models, and research demonstrating the effectiveness of this intervention model, it is arguable that all intervention 
programs should be formulated with parents' perspectives in mind, and should be evaluated using both child progress and parent input.

Parent involvement. Given the growing evidence on the effectiveness of familycentered models, it is critical to involve parents as much as possible. Parents are a critical component to interventions, and when parents serve as co- or primary-intervention agents, studies indicate more positive child and family outcomes (Dempsey \& Keen, 2008; Dunst et al., 2007; McConachie \& Diggle, 2006). There are often barriers, which may prevent or inhibit parents from fully participating in interventions for their children. Through examining parents' perceptions of interventions and potential and existing barriers to participation, we may gain an understanding of how to implement interventions in a way so that barriers are minimized, allowing parents participate to the full extent.

Parents' perceptions of interventions. While the most effective interventions are informed by parents' needs and goals (e.g., Dempsey \& Keen, 2008), interventions do not always include parents' perspectives in the planning and evaluation phases, and some research indicates that parents of children with ASD may be dissatisfied with some aspects the interventions they are receiving. Coogle and colleagues (2013) utilized open-ended survey questions to qualitatively examine parents of children with ASD's experiences with EI. The two themes that emerged for parents' negative ratings of EI were dissatisfaction with EI services and, specifically, a lack of individualization of interventions for children with ASD, and dissatisfaction with service providers. Parents expressed that they desired more qualified service providers and more services and interventions that specifically targeted children with ASD.

There is also some evidence that parents of children with ASD may have significantly different experiences and outcomes in EI (Bougher-Muckian et al., in press; Coogle et al., 2013; 
Epley et al., 2011). Similar to Coogle and colleagues (2013), Bougher-Muckian, Coogle, Floyd, and Root (in press)'s study examined the experiences and outcomes of EI for parents of children with ASD; however, in this study, they were interested in examining the unique outcomes of this group through comparing their perceptions of EI outcomes and helpfulness to that of parents in other disability categories. Significant differences were found in parents' perceptions of how receiving EI services helped them understand their children's rights, communicate their child's needs, and promote their children's development. More specifically, parents of children with ASD rated EI as significantly less helpful in these outcomes than did parents in other disability categories. One possible explanation for the differences found in EI helpfulness between groups is that parents of children with ASD may not be receiving EI services that are tailored to fit the needs of children with ASD (Coogle et al., 2013).

While both Coogle and colleagues (2013) and Bougher-Muckian and colleagues (in press) examined parents' experiences with a broader type of intervention (i.e., EI), other studies have examined parents' perspectives on more specific intervention programs to determine if parents view these interventions as effective and what specific aspects of these programs they find effective and helpful. For instance, Whittingham and colleagues (2009) conducted a mixedmethods study examining what aspects of their Stepping Stones Triple P program (a social and behavioral intervention for children with ASD) parents found most helpful and which aspects they found least helpful. After analyzing open-ended survey responses, primary themes that emerged for positive feedback were improved child behavior, better understanding and use of positive parenting methods, and the relationship formed with the therapist. Three themes emerged for negative feedback: desiring greater individualization and focus on children with ASD, increasing the focus on emotion regulation rather than simply behavior, and changing the 
length of time spent in training sessions. The findings on parents' perceptions of Whittingham and colleagues' Stepping Stones Triple P program have important relevance to this study. First, parents in this study reported a desire for greater individualization for children with ASD, as did parents in the study by Coogle and colleagues (2013). Ultimately, if parents are dissatisfied with the level of individualization they receive in their EI services, this may act as a barrier to their participation. The potential process through which dissatisfaction presents a barrier to participation is of interest to the current study. Parents also reported a desire for interventions to improve the emotional outcomes of their children, rather than simply improving behavioral outcomes. There is a significant lack of research focused on how EI addresses the emotional competence of children with ASD, and, ultimately, how satisfied or dissatisfied parents are with this component of EI; this is another void in the literature that this study is attempting to fill. This research is important given that parents' perceptions of EI may influence their involvement, and ultimately their child and family outcomes after EI.

Research indicates that parents of children with ASD have diverse experiences with interventions, rating some aspects of interventions as positive and some aspects of interventions as negative (Bougher-Muckian et al., in press; Coogle et al., 2013; Whittingham, et al., 2009). Parents of children with ASD appear to have significantly different experiences and challenges with interventions than do parents of children in other disability categories (Bougher-Muckian et al., in press; Coogle et al., 2013). One common theme in the literature is that parents desire interventions that are more focused on treating children with ASD and intervention providers who have greater training in ASD (Bougher-Muckian et al., in press; Coogle et al., 2013; Whittingham, et al., 2009). Although qualitative research into parents' experiences in interventions for their children with ASD has made significant progress, more research into this 
area is needed. Much of the research on this subject deals with understanding parents' experiences with interventions focused on overall child development, with little focus on socioemotional interventions and children's socio-emotional outcomes. Moreover, given the importance of parental involvement (e.g., McConachie \& Diggle, 2006), there is a need to understand the barriers that parents face related to participation, and how their perceptions of interventions impact their involvement.

\section{Theoretical Sensitivity}

When EI is not effective in promoting children's development or involving parents, this can create stress for all parties. Family stress theory can be utilized to understand the complex interactions between ASD, parenting, perceptions of interventions, and child outcomes. According to Hill's $(1949,1958)$ ABC-X model, the degree to which family stressors (A) influence the development of a stress-related crisis $(\mathrm{X})$ depends on existing resources (B, i.e., social support, resources within the family) and a family's' perception of the stressor and existing resources $(\mathrm{C})$. In the case of parents of children with disabilities, the degree to which their child's disability creates crisis within the family is dependent of their existing resources, internal (e.g., emotional well-being) and social, and their perception of their efficacy in parenting a child with a disability. Presumably, if parents have few emotional and social resources, they are likely to have more negative perceptions of parenting a child with a disability and lower parenting self-efficacy, leading to a higher likelihood for internal crisis, influencing the parentchild relationship and, ultimately, child outcomes.

Interventions are an important potential social resource for both parents and children, providing an avenue to seek guidance in parenting, while also promoting important developmental skills in children (Dempsey \& Keen, 2008). In the case of socio-emotional 
interventions for ASD, having positive experiences with interventions may both improve parents and children's perceptions of everyday stressors and their ability to handle stress, and increase their internal resources (e.g., emotional well-being and regulatory strategies). Effective familycentered and relationship-focused interventions should increase social support and parenting skills and improve parent-child interactions (Dempsey \& Keen, 2008; Mahoney \& Perales, 2003), part B of the ABC-X model (social resources). And research by Myers, Mackintosh, and Goin-Kochel (2009) suggests parents report lower levels of stress when they have higher levels of social support. On the contrary, having negative experiences with interventions may either deplete, or do little to increase, families' social and emotional resources, and have no positive effect on their perception of their ability to handle stressful life events.

An important component of family stress theory, and thus an important component of research on families' experiences with intervention, is that it is not only what social resources exist, but also how a family perceives these social resources, in this case interventions, that influences their outcomes. In order for interventions to be effective in promoting the socioemotional outcomes of children with ASD, families must perceive those interventions as effective and hold positive views regarding various components of interventions. If parents perceive interventions as effective, they may be more likely to participate in EI and future interventions, and parent involvement has been linked with child and family outcomes in EI, with involvement being positively related to child and family outcomes (Dempsey \& Keen, 2008; Dunst et al., 2007; McConachie \& Diggle, 2006). Hence, in the current study, it was paramount to understand not only the past experiences of parents in interventions, but also their perception of those experiences and their perceptions of how these experiences positively or negatively affected their children's socio-emotional outcomes. 


\section{Researcher Positionality}

I came to researching the experiences of parents of children with ASD in EI after working with children with ASD for several years in a variety of settings. I first worked with children with ASD as a public preschool special education teacher. During this time, I was able to see first-hand how children with ASD struggle with social interactions. Several of my students had difficulty playing cooperatively with their peers without getting into a verbal or physical argument It was from these experiences as a teacher that I first realized the impact that emotional dysregulation can have on children's social skills.

In more recent years, as both a developmental specialist for West Virginia Birth to Three and a counselor of children with ASD I have realized how important parents are in the intervention process. As Sheffield Morris and colleagues (2007) note, parents are arguably the most important agent in helping children develop emotional competence. In both of these settings, I saw significantly greater progress in children's social and emotional goals when the intervention process was family-centered and parents were highly involved.

As a graduate student, I came to this research question after several years of researching parents of children with ASD's emotion socialization practices using quantitative methodology. I was first interested in comparing the emotion socialization practices of parents of children who are typically developing to the emotion socialization practices of parents of children with ASD. While we did find significant differences in emotion socialization between the two groups, particularly in regards to parents' responses to their children's expressions of anger and fear (see Bougher-Muckian et al., 2016), we still ended up with more questions at the end of the study.

From these emerging questions, we created another quantitative research study. In this study, we utilized survey design to examine how children with ASD's adaptive level influenced 
parents' attributions for their children's emotional expressions (i.e., why their children are expressing these emotions). Again, we did have some significant findings. Specifically, high adaptive level was related to parents' views of children's negative emotionality (i.e., sadness, anger, fear) as being unstable and modifiable (Bougher-Muckian et al., 2017). However, again, we ended up with additional unanswered questions. We knew that in this sample of children with ASD, adaptive level seemed to be influencing parents' perceptions of how much their children's negative emotional expressions could be altered; however, we were still unsure of what other factors were at play in this relationship. How does intervention fit into all of this? Were there other factors influencing how parents perceived their children's negative emotions?

Together with my graduate advisor and other mentor researchers, we decided to explore parents of children with ASD's experiences with EI, again utilizing a quantitative survey approach. We found that parents of children with ASD reported significantly poorer EI outcomes than did parents of children with other disabilities (Bougher-Muckian et al., in press). As with the previous quantitative studies, this study led to more curiosity and new research questions. What is causing these differences in the experiences of parents of children with ASD in EI? How can we improve the EI outcomes of children with ASD?

After completing several quantitative studies where we were not able to get at the "big picture" of parents' experiences in EI for children with ASD, we decided that we needed to change our approach in our next study. Maybe looking at simply the numbers was not showing us the full experience. We needed to use a different approach. Using a more open-ended qualitative approach would help us to better understand parents' experiences with EI for their children with ASD.

\section{Epistemology}


Semi-structured interviews were used to answer the research questions about parents' experiences with EI and goals for their children with ASD. This method allows researchers to gain an in depth understanding of parents' lived experiences. Kvale and Brinkmann (2009) relate narrative interviews to the metaphor of a traveler, stating that in this method the researcher "walks along with [their participants], asking them questions and encouraging them to tell their own stories of their lived world" (p. 48). Moreover, from this perspective, data collection and data analysis phases are not to be considered as two distinct phases, but as interconnected (Kvale \& Brinkmann, 2009).

Interviews have been used in past research to examine parents' views on the effectiveness of interventions. For instance, Whittingham and colleagues (2009) utilized interviews to evaluate parents' perceptions of their intervention at each phase: prior, during, and following the intervention. In addition, there are several studies showing that qualitative methodology, specifically interviews are an appropriate means to examine parents' experiences in raising a child with ASD (Gill \& Liamputtong, 2011; Woodgate et al., 2008). Using qualitative methodology, and more specifically, narrative interviews allows the "voices of those who are silenced... and marginalized" to be heard (Gill \& Liamputtong, 2009, p. 311). Qualitative research indicates that parents of children with ASD have experienced significant social isolation and stigmatization (Myers et al., 2009; Woodgate et al., 2008). Thus, using narrative interviews may allow us to gain a more realistic and in-depth understanding of the real-life experiences of parents of children with ASD and better understand their perspectives on their experiences with EI.

\section{Summary}


One of the primary ways in which children gain emotional competence is through the process of emotion socialization, of which parents are a primary socialization agent (Sheffield Morris et al., 2007). Specifically, parents' supportive and non-supportive emotion socialization practices have been linked to children's long-term outcomes (Davis \& Buss, 2012; Jones et al., 2002; Leerkes et al., 2009). Thus, it is critical to examine the child-related and parent-related factors, which contribute to parents' emotion socialization practices. Understanding the process, and factors that contribute to emotion socialization may be even more critical for children with ASD, given that they often struggle in areas related to emotional skills such as perspectivetaking, emotion regulation, and expression of negative emotion (Pouw et al., 2013; Samson et al., 2014; Samson et al., 2015; Tanaka et al., 2012).

Raising a child with a disability can be difficult for parents in that it presents unique challenges; thus, parents may feel stress in trying to adapt and find new ways of parenting. In accordance with family stress theory, if parents perceive stress as insurmountable, they are more likely to feel that they cannot handle this challenge and these perceptions may result in crisis (Hastings \& Brown, 2002). On the contrary, if individuals have high levels of social support, they are less likely to perceive stressful events through this lens, and are more likely to develop more positive coping strategies for dealing with stress.

One potential social resource for parents of children with ASD is interventions. Familycentered interventions, those that include a focus on family needs and goals, and utilize high levels of parental involvement, have been shown to result in more positive child and family outcomes (Bruder, 2000; Dempsey \& Keen, 2008; Dunst et al., 2007; Farrell 2009; McConachie \& Diggle, 2006; Talay-Ongan, 2001). In order for family-centered interventions to be most effective, parents must be involved as much as possible; however, research indicates that parents 
often face significant barriers to involvement, and if they hold negative perceptions of interventions, this can significantly influence both their level of participation and the interventions' effectiveness (Coogle et al., 2013). Parents of children with ASD may rate interventions significantly less positive than parents of children with other disability categories (Bougher et al., in press), which may be a result of a lack of individualization and focus on the specific needs of children with ASD (Coogle et al., 2013). Given the difference in ratings of helpfulness of interventions for families of children with ASD, and the potential effect of perceptions on child and family outcomes, it is critical to continue to research the complex interactions between family needs, perceptions of EI and parent involvement. It is possible that parents' negative perceptions of interventions may act as a barrier to their involvement, thus making interventions less likely to result in positive outcomes. The most effective way to understand the complex experiences of families of children with ASD is through the voices of the families themselves. In giving parents a voice on this complex subject, we can hope to untangle some of the complexities in their experiences with interventions for their children with ASD. Specific research aims and questions are described in detail in the following section.

\section{Research Questions}

This study utilized qualitative methodology and, more specifically, GTM (Corbin \& Strauss, 1998; Glaser \& Strauss, 1967) to understand the process and interactions which may exist between three components related to EI: parents' perceptions of children's developmental needs and goals, parents' involvement, and parents' perceptions of satisfaction and dissatisfaction with interventions. Research suggests that parents of children with ASD face significant barriers to participation in EI (e.g., Dempsey \& Keen, 2008; McConachie \& Diggle, 2006), and that they are dissatisfied with certain aspects of EI, particularly the lack of 
individualization and provider training related to ASD (e.g., Coogle et al., 2013), and a lack of focus on skills related to emotional competence (e.g.,Whittingham et al., 2009). Little is known about how parents' perceptions of children's emotion-related developmental needs, and perceptions of satisfaction and dissatisfaction with EI act as barriers to their level of involvement, and how these constructs may interact with one another. The purpose of this study was to untangle some of the complexities involved in families' experiences and involvement with EI. This study utilized GTM to answer the following research questions:

RQ1: How do parents perceive their involvement in EI?

RQ2: How do parents perceive their satisfaction with EI?

RQ3: What are parents' goals for their children?

RQ4: How do parents describe their transition into and out of EI? 


\section{Chapter III}

\section{Method}

\section{Participants}

Twenty parents participated in the study. A subset of these participants also completed follow-up interviews $(n=13)$. See table 1 for participant demographics. Participants were recruited from parents of children with ASD, who received EI services within the past seven years. Parents reported on their child's ASD diagnosis. Within qualitative studies, participants are viewed as "meaning makers" (Warren, 2002, pg. 83), and within GTM, a theoretical sampling technique (using purposeful sampling that allows for a well formed theory) is often used (Creswell,1998). In this study, parents of children with ASD are the experts on their experiences with EI.

The sample size for this study is consistent with other qualitative studies. Qualitative studies utilizing interviews for data collection typically range between 20 to 30 participants; this is often an appropriate number to achieve data saturation (i.e., the point where no new data or themes emerge; Creswell, 1998). In this study, the sample size $(\mathrm{N}=20)$ was adequate to achieve data saturation.

Parent demographics. The majority of the parents were mothers (mothers, $n=19$, fathers, $n=1$ ). Mean age for parents was 35 years (range $=26-50$ years). All of the parents in the sample identified as Caucasian and non-Hispanic. The mean annual income for parents was $\$ 68$, 000 (range from $\$ 15,000-\$ 150,000)$. Five percent $(n=1)$ of the parents had an annual income between $\$ 10,000-\$ 25,000$. Nine parents $(45 \%)$ had an annual income between $\$ 25,000-\$ 50,000$. Two of the parents $(10 \%)$ had an income between $\$ 50,000$ - $\$ 75,000$. Three of the parents $(15 \%)$ had an annual income between $\$ 75,000-\$ 100,000$. Three of the parents $(15 \%)$ had an annual 
income of between $\$ 100-\$ 150,000$. Two of the parents (10\%) had an annual income of over $\$ 150,000$. All the parents in the sample completed either some college or had a college degree or higher (some college, $n=8$; college degree, $n=9$; graduate degree, $n=3$ ).

All of the participants in the sample were residents of West Virginia. A little over half ( $n$ =12) of the parents were from the greater Morgantown, WV region (Monongalia County).

Monogalia county is a higher income region in West Virginia, with a higher median income than the state of West Virginia, as a whole (Monongalia County, median income $=\$ 47,060$; West Virginia, median income $=\$ 42,644$; U.S. Census Bureau, 2017). However, the median income in Monongalia County, WV is still well below the national average of $\$ 57,617$ (U.S. Census Bureau, 2017). The remaining participants were from the following West Virginia counties: Marion, Wood, Preston, Kanawha, Putnam, and Raleigh.

Child demographics. The mean age for children that parents reported on was 6 years (range $=3-10$ years). The majority of the children parents reported on were male (male, $n=17$; female, $n=3$ ). This is consistent with the prevalence data on ASD, with males being four times more likely to be diagnosed with ASD than females (CDC, 2014). The majority of parents described their children as Caucasian and non-Hispanic $(n=18,90 \%)$. The remaining parents described their children as Bi-racial and non-Hispanic (Black and white, $n=1$; Philippine and white, $n=1)$.

\section{Procedure}

Advertisements, along with an overview of the study, were distributed via email or inperson to parents of children with ASD who have recently received EI services. Advertisements were distributed via EI providers and administrators in West Virginia Birth to Three. Advertisements were also posted at a variety of community locations (e.g., doctors offices, 
community centers) and posted to social media (i.e., Facebook). Eligible participants were contacted via phone or electronic mail to schedule their initial interview, and then at a later date to schedule a follow-up interview. Participants completed a demographic survey, an initial interview, and a sub-set of the participants also completed follow-up interviews $(n=13)$. The majority of the initial interviews were completed via phone (phone, $n=19$; in person, $n=1$ ). All follow-up interviews were completed via phone. As an incentive, participants received a $\$ 50.00$ gift-card for the initial interview and a $\$ 50.00$ gift card for participating in a focus group. Interviews and follow-up interviews were audio recorded and transcribed verbatim. NVivo@ software was utilized for data analysis.

\section{Measures}

Demographic questionnaire. Basic demographic information was collected, including race, ethnicity, census region of residence, parent's education level, parents' annual income, occupation and employment status, child gender, child age, and parental age (see Appendix A).

Open-ended interviews. Open-ended interviews were utilized to understand parents' perceptions related to areas of socio-emotional need for interventions, barriers to participation in EI, and areas of satisfaction and dissatisfaction with EI. According to Warren (2002), within qualitative research, interviews should be utilized as a method when the goal of the study is to better understand themes that emerge in the experiences and perspectives of participants. Interview questions were written in a way to allow for the researcher to understand participants' perspectives and experiences related to the research question (see Appendix B for list of interview questions). Three types of questions were included in the interviews: main questions (questions related to the research questions in the study), probing questions (questions to clarify), and follow-up questions (questions to prompt the participant to expand on the subject). Each 
interview lasted between 45-60 minutes.

Follow-up Interviews. A sub-set of the participants participated in follow-up interviews $(n=13)$. The follow-up interviews were used as a method of data triangulation to verify emerging themes from the initial interviews. The interviewer gave an overview of some the preliminary findings and themes that were emerging from the interviews. Participants were given the opportunity to expand upon their previous responses, and verify or negate the researcher's interpretations.

\section{Data Analysis}

Data was analyzed using GTM (GTM; Corbin \& Strauss, 1998; Glaser \& Strauss, 1967). GTM is an appropriate method to use in this study because little is known about how the three concepts of parents' perceptions of EI, parents' socio-emotional goals for their children, and parents' participation in EI relate to one another; thus, new theories and hypotheses need to be generated. The result of GTMs is to create a theory to explain a social phenomenon and develop “a plausible relationship among concepts and sets of concepts" (Creswell,1998; p.56). This theory is typically presented in the in the form of a narrative, visual or hypothesis/hypotheses (Creswell, 1998; Strauss \& Corbin, 1990). The phenomenon that was under study in this project was parents' perceptions of EI, thus this study produced a theory to explain parents' goals for their children and perceptions of EI.

As with any qualitative project, data collection and analysis occured simultaneously. Thus, the researcher began transcribing interviews soon after they concluded in order to begin generating codes and early hypotheses regarding what is going on with the data. Early hypotheses were tested in follow-up interviews, so the interview schedules differed somewhat based on when participants were interviewed. Data collection continued until data analysis 
suggested the point of theoretical saturation occurs, which was the point that incoming data no longer added new information (Corbin \& Strauss, 1998).

Coding. The researcher read the entire interview transcript over once without applying any codes. Then, open, axial, and selective coding were used to analyze the data. During the first stage of analysis, the open coding phase, the researcher denoted a major theme (i.e., code) to each sentence or line of the interview transcript (Kvale \& Brinkmann, 2009). In the axial phase of analysis, these interview codes were reviewed to find common themes across participant responses and lines of the interviews (Kvale \& Brinkmann, 2009). The subthemes within the individual lines of the interview were combined into larger themes across the interviews and across participants. During this phase, the interviews were re-examined in relation to the research questions of interest. In accordance with GTM, the final phase of the analysis - selective coding -included the development of a theory (e.g., process-model) about parents of children with ASD's experiences and perceptions of EI.

Authenticity Measures. Qualitative researchers do not focus on validity, but rather on the authenticity of the research. Authenticity means that researchers are coding the data based on the participants' perceptions rather than the assumptions of the researcher (Kvale \& Brinkmann, 2009). One way qualitative researchers can ensure their projects are authentic is by using triangulation. Triangulation is used to cross-reference data and themes that are emerging within qualitative research, and involves verifying themes from multiple sources or investigators (Creswell, 1998; O’Donoghue \& Punch, 2003). The primary investigator used triangulation by verifying emerging themes throughout the analysis process with a second researcher, a committee member of the dissertation (not involved in the interview process) and completing follow-up interviews. 
A subset of the participants completed follow-up interviews. In these sessions, the primary investigator reviewed the themes that emerged from the interviews, and provided the participants with an opportunity to confirm or negate these interpretations. Participants were also be given an opportunity to elaborate on their responses. The transcripts from the follow-up interviews were then reviewed line-by-line and open, axial, and selective codes were applied to determine if there were new themes emerging, or if the follow-up interviews were consistent with the initial interviews. The themes from the follow-up interviews were consistent with the initial interviews, further ensuring that data saturation had occurred and no new participants were needed.

Peer review was another step utilized to ensure data authenticity. During each phase of coding (open, axial, and selective) the interviews, a secondary researcher (a committee member) reviewed the codes. In each phase, she reviewed the codes and we discussed them. She provided constructive feedback to help me refine and strengthen my codes and the theory that was generated from the interviews. 


\section{Chapter IV}

\section{Results}

This Grounded Theory study focused on understanding how parents perceive their involvement in, satisfaction with, and transition into and out of EI. Two primary research questions were asked. First, participants were asked about their experiences with EI. Next, they were asked about the goals they had for their children in relation to EI. Based on the interviews a theory was developed to describe and understand the experiences of parents in EI. Based on the data, this theory illustrates how participants described their experiences with EI in three distinct periods: before, during, and after EI (see Appendix C). Before EI, the primary experience was Frustration Surrounding the Initial Referral, leading some parents to seek out options on their own. For example, one parent said, "If I had known what Birth to Three would do for him...then I would have definitely [initiated the program earlier]." This frustration, however, evolved to a high level of satisfaction when discussing services during EI. The primary experience during this phase was Collaboration Between Service Providers and Family Members. For example, another parent said "I felt very comfortable with the [service providers] I had. They talked us through everything and there was never a point where we didn't feel comfortable." Finally, after their children aged out of EI (age three), the primary experience was Letdown after EI, as most ( $n=$ 18) of the parents' satisfaction with services changed once again to frustration, this time based on the challenges with accessing services for their children within public school setting. As one parent looked back on her daughter's transition into school, she described fear and frustration that EI was over: "There were concerns on our part," and uncertainty over what public school would bring, “...public school... which did not work out well for her... as a parent, couldn’t it be birth to five?". 
Similarly, parents described the goals they had for their children in three distinct periods. Before EI, parents described areas of delay and goals for their children's development as their reasoning for pursuing EI services. The majority of these parents' goals focused on language and communication, while a few focused on goals for motor skills. During EI, parents described the goals they were working on with their children through EI. Again, social, communication, and language goals were a primary focus for parents. Finally, after aging out of EI, parents described both short-term and long-term goals for their children. The majority of these parents described social, language, and communication goals, while a few parents also discussed academic goals for their children.

\section{Goals Before EI}

Half of the parents described their goals for their child prior to EI. Most of these parents described communication and language goals for their children before starting EI and described

these goals as one of the primary motivators to enrolling in EI services. As one parent described, "We started EI when [my child] was 15 months because of a speech delay (012)." Some of these parents already began working on these goals and working on interventions for communication and language prior to beginning EI. For instance, one parent noted that their child was "doing basic baby sign language because he couldn't tell me what he wanted (07)."

A minority of the parents also described having motor goals $(n=3)$ for their children prior to starting EI. For these parents, their concerns for motor development were the motivating factor for initiating and enrolling in EI services. For instance, one parent described that their child was "not walking at 18 months so we got her an evaluation from West Virginia Birth to Three (010)."

\section{Frustration Surrounding Initial Referral}


Before EI, 15 parents described feelings of frustration in gaining an initial referral into EI services. Two main themes emerged in this stage: frustration with professionals for not referring and parental agency in starting EI.

Frustration with professionals for not referring. Many of the parents $(n=12)$ discussed challenges related to professionals not referring. Parents described two specific areas of frustration: (1) frustration with pediatricians for not validating their concerns about their children's development and not providing referrals and (2) frustration with pediatricians not seeing the same signs of ASD in their children that parents were seeing, and thus not referring them to EI or for further ASD evaluation. One parent described her experience with the pediatrician not referring as early as they thought was needed stating "At two I talked to our pediatrician, and the pediatrician said 'Is he putting words together like 'Mommy look or Mommy come,' and he was like 'It'll come, just watch for it. I will see you at your three-yearold well visit (02)." Another parent expressed similar issues, "I mean doctors. 'Oh, she is only two. Let's wait, let's wait.' And I'm the type of person that when I want something done, I want it done now. And then she just continued to regress (05)." These parents expressed concerns about their children's development and/or their perception of delays to pediatricians at earlier ages and were told their children would progress with time, and given no guidance toward, or referral to, EI services.

Other parents expressed frustration that their pediatricians did not feel their children had ASD due to the doctors feeling that they did not have all of the early signs of ASD. These parents did see some of the early warning signs of ASD in their children and were frustrated when their doctor did not see the same concerns. 
Around the time he was two... [The pediatrician] had, like, 12 questions and she said 'No he doesn't have autism because he's looking at me,' even though some kids might look like they're looking at you but they're looking right through you because he's thinking about trains...So she said he did not have autism, and the following day another pediatrician told him he did and sent him to the clinic and he was formally diagnosed. 08

As these parents described in their interviews, many of the parents felt high levels of frustration with trying to gain access to EI. Although many of these parents had concerns for their children's development, according to the parents, their pediatricians did not share these concerns and, in many cases, did not listen to the concerns of parents. Thus, pediatricians did not refer them for EI services or for further evaluation for ASD, which delayed the start of EI services. Many parents, however, turned their frustration into advocacy on behalf of their children.

Parental agency in starting EI. After disappointing conversations with pediatricians who did not refer their children for EI, and due to increased concern for their children's development, several parents $(n=12)$ self-referred to EI services. Three main themes emerged in this category: 1) self-referring after disappointing interactions and no referral from the pediatrician, (2) frustration in communication with family about their concerns, and (3) relying on the help of other parents and social media to gain access to EI.

Several parents described having to self refer after pediatricians and family members tried to tell them that they should not be concerned. One such parent stated that she had to self refer because the "pediatrician absolutely refused to listen" when her son was not crawling and meeting other milestones such as babbling at a year old (016). She went on to describe how the pediatrician said, "He is a boy. Boy's take longer [to develop]" (016)." Another parent described 
similar issues stating that it took her a while to self-refer because she was listening to other family members who kept insisting that her child was simply developing a little late:

I kept listening to other people, who said 'He will talk. He is just a late bloomer.' And I said 'I don't think so.' I referred myself to Birth to Three...I wish I would've utilized the services earlier than I did....I wish my pediatrician would've recommended it earlier because maybe he would've been more advanced than he is now. I self referred him. His doctors didn't. - 07

This parent, like others, expressed frustration about a late start to EI because of the pediatrician not referring. Parents noted that "EI is critical." In fact, they believed that their children might have made even more progress had they been able to receive services earlier.

Several parents expressed frustration that they found out about EI from other parents and through the use of social media, rather than through their pediatricians.

I think I was just venting on Facebook... and there was a friend of a friend who had three sons with autism and she was like....'Well the first place to go is, have you heard of this program called Birth to Three? They will evaluate her.' And I was like, 'No I haven't heard of this.' -05

For this parent, and others, social media and communication with other parents was paramount in helping them understand the services available to their children and understand the process of self-referral. Even though the parents in this study faced significant challenges and frustration related to gaining initial referral into EI, all of these parents in this category took it upon themselves to ensure that their children received the services they felt were needed to help their children develop. They did not let issues with professionals keep their children from getting the services they needed. 


\section{Goals During EI}

In order to understand parents' experiences, involvement, and satisfaction during EI, it is important to understand parents' goals for children during EI. A majority of parents (14) described their goals during EI. Most of these parents described social and language/communication goals as their primary goals in EI. One parent emphasized the importance of communication as a goal for EI, "Obviously, the one goal we wanted to accomplish was getting [our child] speaking again. He had kind of regressed to where he wasn't speaking, and we were able to accomplish that goal (04)." Another parent described that for her child, working on the "pronunciation of specific sounds" significantly helped their child communicate their wants and needs such as working on pronouncing "the $\mathrm{K}$ in 'MilK (07)."

One parent discussed their goals for their child's speech and what activities were most effective toward working on this goal:

She just didn't talk...then I noticed my husband would just talk to her. Like 'This is a pen. We use this to write on paper.' Just a running narrative of everything we do. So she knows what words are, and what they mean. I am 'standing up, this is up, and now I am sitting down.' I didn't think about verbalizing and running commentary. (01)'

In this parent's experience, speech was very important since their child was non-verbal. During EI, the parents were able to work with their child on increasing her speech by using a running narrative approach where the parents described everything they were doing.

Some parents emphasized the social aspect of their goals for their children's communication. For these parents, they saw a clear connection between improving their children's speech and language and the quality of their children's social interactions with family and friends. One such parent described this saying "I think one of his first goals was calling us 
Mama and Dada, and now it's communicating how to tell the other kid that you want to play with that toy (09)." As this parent described, she felt that their "first goals" should revolve around language and communication because if their child's language and communication improved this, in turn, would also improve their social interactions with family and peers and their overall social competence.

Other parents described a similar thought process stating that their primary goal was language and communication, and that they felt that working on language skills would indirectly improve their children's behavior. As one parent described, "I think his main goal was speech. We thought a lot of his other behavior frustrations would go away when he could finally communicate" (012). In this parent's experience, most of her child's behavioral issues were caused by being unable to communicate wants and needs; therefore, teaching him some form of communication reduced his frustration, and ultimately his behavioral issues.

A small minority of parents also discussed sensory goals during EI. One parent described that one of the focuses of EI was to focus on getting their child "eating different foods and he had a pretty strong gag reflex and we were able to help with the occupational therapist to overcome that (04)." Another parent described that prior to EI, they did not realize that their child had any sensory related challenges, and EI was able to address these issues and focus on goals related to this area:

Birth to Three was helpful in getting me to deal with these issues with [child name], especially his sensory issues. I would never have even considered that. It was interested to have people asking us does he have any particular behaviors that are sensory seeking. 02 
For this parent, service providers were able to educate them to help them better understand some of the sensory issues their child was exhibiting that they were not aware of before EI. Once the parent had this understanding, they were better able to focus on how to help their child with their sensory needs and work on specific sensory related goals.

\section{Collaboration Between Service Providers and Family Members}

During EI, all 20 of the parents interviewed expressed satisfaction with EI services. Parents described high levels of collaboration between family members and service providers and, as a result, described positive child outcomes from EI. Parents described three areas of high satisfaction related to collaboration between service providers: family involvement, trust between provider and parents, and satisfaction with the amount of progress their children made by the end of the program.

Family involvement and skilled service providers. The majority $(n=18)$ of parents expressed satisfaction with the level of collaboration between service providers and family members. Parents described satisfaction related to two main areas: family involvement and satisfaction with skilled service providers. Some parents mentioned that in addition to parents, the providers also involved other members of the family. One parent described that they "had so much fun. They really involved the other two [kids] in everything (015)." Another parent described that the providers went out of their way to incorporate both her other children and grandparents stating that the providers went "above and beyond to incorporate our older son and my elderly mother who lives with us (03).”

Several parents stated that they were very involved in goal planning, and that EI goals were planned through a collaborative process between parents and service providers. For instance, one parent discussed their experience during the initial evaluations and planning of the 
initial goals, "[Goal planning] was definitely a group discussion. We talked about where we wanted him quickly, his short-term goals. We also thought about long-term goals. We talked about it as a group before anything was written down." (018). Another parent had a similar experience with planning the goals after initial evaluations stating, "When they did their initial evaluations, they asked me, 'As the parent, what goals do you want to see for this?'... We worked together to form each of the goals" (015). Parents also noted that the practitioners asked parents for their input, while also using their professional expertise to understand what additional goals might need addressed. One such parent expressed that, "It was a team effort. I would tell them what was important to me... based on his age and our daily living, they would share what presented as a problem to them, and we would put the two together" (019).

As aforementioned, other parents mentioned the high level of skill that service providers had in collaborating with parents. For instance, some parents described that service providers were very flexible in the way that they provided services. One such parent mentioned that even on days where their child did not want to do activities with the provider, the providers would give them activities that the parents could complete at home at a later time when their child was in a better mood:

If there was a day that she was not going to be getting anything done therapy-wise, then it would be, 'Here is something to work on before the next time we come back.' We always appreciated having things to work on when there wasn't a therapist in the home. We always wanted to be engaged, and they always welcomed that. -017

In addition to flexibility in activities, several parents also discussed professional skills when they mentioned that the providers not only helped their children, but that they felt that, as a parent, they also learned a great deal from the providers. Several parents stated that they learned 
parenting strategies and an understanding of strategies to help children with ASD. One parent described how she didn't "know anything about autism...." or "anything about the delays, and they were just a wealth of knowledge. They didn't just help him....I learned so much (010).” Another parent described, EI helped her "give her child what she needed (012)." She went on to say, "I was able to help my own child when these services were no longer available. We still use countdowns for transitions... and timeouts for minutes his age." Several other parents noted that EI helped them gain an understanding of characteristics and strategies to help their children with ASD. In both of these parents' experiences, having these service providers was an invaluable tool in teaching her about her child's ASD and providing them with parenting strategies. They described really valuing the fact that the service providers were there not only for their children, but to help them learn as well.

Trust between service providers and parents. Another important aspect of collaboration that parents discussed was trust between providers and parents. Eighteen of the parents discussed a high level of trust between parent and practitioner. Parents expressed that they felt very comfortable throughout the entire process bringing up any concerns they had about goals to the service providers. If parents did not agree with one of the goals for their children, they felt that if they brought this up to the practitioners then this issue would be addressed appropriately. For instance, the following parent described feeling very comfortable addressing concerns about goals with their providers:

I think it was a pretty open dialogue, and I felt very comfortable with the people I had and the things I needed to do. They talked us through everything and there was never a point where we didn't feel comfortable. They would suggest things and sometimes we 
wouldn't be able to do that or they would say 'I don't think we need to go down that path yet.' We were very honest with each other. -09

As this parent and others described, they developed a very positive relationship with their service providers, a relationship built on honesty, trust, and collaboration. This foundation of trust and honesty made it easier for parents to communicate with their providers about their concerns and goals for their children's development.

\section{Child progress as a result of collaboration and skilled service providers. Sixteen}

parents discussed that, because of high levels of collaboration and skilled service providers, they felt that their children were able to make significant progress by the end of EI. Parents discussed progress related to three areas: communication/language, behavior, and family functioning.

Several parents noted that after EI, their children's communication and language were improved. One parent described a stark difference in language from beginning to end of EI stating that "he wasn't talking at all when he started. By the time he finished he was talking nonstop, complete sentences. He never stops. (015)" Another parent also stated that EI improved her child's communication, "He was able to communicate which beforehand was very frustrating, and after it helped with the meltdowns (011)." In this parent's experience, EI improved his communication, and this increased communication also decreased behavioral issues at home such as meltdowns.

Another parent also described increased communication as a result of EI and described how this increase in communication related to their ability to address their child's basic needs and daily living:

He used to just grunt and wouldn't communicate with us if he was sick or hungry or needed something, and now he is able to. He was almost nonverbal when he started, and 
now, he does not stop talking. Him being able to use his language functionally has been a game changer. He can tell me when he is hungry, he can tell me when he is tired. I cannot thank those providers and service coordinators enough for ensuring that that happened...While before he had a lot of language, at two he could read sight words, he knew his alphabet, he is a very bright boy, but he couldn't tell us he was hungry. He couldn't call me Mamma. There was that gap there....He still struggles, but it is not nearly where it was before. -09

Other parents described how, through EI, their children were able to make progress in their developmental goals, and that this progress improved their functioning and life as a family. One parent described their experience:

It wasn't until they started working with him that we started to see his personality, his demeanor, and everything change so I totally accredit that to them and how to handle those things...The biggest thing we have gotten has been our ability to enjoy life again...No meltdowns. No freaking out about things. We were actually even able to leave him in the child program on vacation...They have helped him to be more comfortable in his surroundings, to be more aware of his surroundings, helped him to cope and, as a result, they've helped us to become more like a family and doing things like a family, and no one has to try to stay home and miss out on these exciting times. -03

In this parent's experience, receiving EI was able to improve her child's behavior and, as a result, their family was able to function more effectively and "enjoy life again" in situations like family vacations. For this family, and the families above, improving their children's communication and behavior also had an effect on family functioning and made daily living easier; not only improving children's outcomes, but family outcomes as a whole. 
As one parent described, in addition to witnessing child progress, parents were also able to see potential for their child and their goals for the future:

[The program] gave us hope. By the end he was a different kid who continues to grow, and by the end he did things that I never even thought was possible. It gave us hope for the future. It took away the majority of the fears of the road he could have been going down. It changed all of that. -018

Dissatisfaction in EI. Although all of the parents expressed overall satisfaction with EI services, a minority $(n=4)$ parents also described specific areas of dissatisfaction with EI services. Each of these parents discussed issues related to service provider communication. During the interviews, some parents expressed feelings of dissatisfaction with the level of communication between various service providers.

One parent described issues with communication between providers related to goals: We have that overall goal, but everyone has their individual goals. I think sometimes I feel like there is some communication among the team but not as much as between me and...this one or that one...If they could communicate other than just in our meetings, so that you know if they say, 'I know you want him to use one or two word phrases but I'm more focused on him not chewing on his shirt. -03

In this parent's experience, the practitioners communicated at the meetings but she felt that after the meetings their communication was not frequent enough. As a result of this lack of communication, the parent noted that the practitioners were focusing on different goals. The parent described this issue in communication between practitioners as an area of dissatisfaction with EI services. 
Other parents described issues with service provider communication with family members. For instance, some parents described insensitivity in the way that service providers approached discussing potential disabilities and disability characteristics with parents. Parents expressed that they felt that communication of this sensitive information should be done slowly and in a more respectful manner.

One parent described her experience with a specific service provider who did not communicate her child's potential ASD diagnosis in a way that she thought was sensitive:

There was one visit with an OT that... she walked in the door and immediately was like "He has ASD" and left, so that wasn't the best situation so we switched OTs after that... [had] a little bedside manner to say "Hey, I'm observing a couple things that could be potential markers for this, and I recommend you do the following steps or see the following people, guide him and use this direction," instead of just saying he has this and then leaving. -09

Other parents expressed dissatisfaction with the way in which practitioners communicated with their children. For instance, one parent described her experience with a service provider who did not have much patience with her child:

We had another speech therapist come through... and they were doing something and she

[my child] couldn't do it and she [the speech therapist] would get frustrated and just shut the book. She came once and I called my coordinator, and said 'Never again', and she said 'Well, she has to do her eval,' and I said 'We don't need another eval (01).'

\section{Goals After EI}

Twelve of the parents described goals for their children after EI. Some of these parents described long-term goals, while others described goals that were short-term. Language and 
communication came up again as a primary goal for parents after exiting EI. For instance, in the short-term, one parent described that they wanted their child to be "communicating with peers at an age appropriate level" (09). Again, parents emphasized the connection between language/communication and social skills. If their children were able communicate more effectively, this would also improve their social interactions with peers. One parent described this connection between working on language/communication and social interactions stating that they would "like to see [their child] be more social, and obviously increase his vocabulary. He can only say about three words right now (013)."

Another parent described their goals to help their child communicate in social settings: She is nonverbal, and continues to be nonverbal, so one of our main goals is how to communicate. ...We may look at using sign language or other visual mediums to help her communicate. That is our main goal, helping [child name] communicate with us and us communicate with her. -017

Other parents described a connection between working on goals for their child's language and communication and behavioral issues. One such parent described her goals for her child:

Some of our goals, especially right now, where she has aggression issues that we believe stem from her lack of communication ... so our main goal at this time is to get her where she needs to be with her communication to ease some of those boundaries... To get the anger and outbursts under control so she can normally function, not go straight to being aggravated if she can't express what she needs to us. Mainly communication as a longterm goal. -05 .

As this parent described, working on the goal of improving their child's language and communication would indirectly improve their behavior. Most of their child's behavioral issues 
"stem from her lack of communication," thus, if their child is provided with the tools to communicate her wants and needs more effectively, these behavioral issues and aggression would decrease.

Other parents discussed goals more directly related to social skills. Some of these parents mentioned the importance of helping their children understand social cues, while others emphasized the importance of positive relationships and interactions with peers. One parent described her goal for friendships stating that she would like her child to "have a friend. That would be nice... There is one little girl her age, and she will run around with her but the minute the little girl wants to talk, or share, she's like, 'I'm out' (01)."

Another parent described the importance of helping her child continue to understand social cues, and that this, ultimately, will improve her child's social competence:

I would say our main goal is to continue to work on, and be aware of, social skills. There are still moments when he needs to be cued in, or talked to, or coached. That is really important to me that he continues to grow with his social skills. -03

For both of these parents, relationships with peers and overall social skills are important goals that they are continuing to focus on after aging out of EI.

A few parents also described goals related to cognitive skills and academics. Some parents emphasized the importance of having their children be included in the general education classroom as much as possible. One parent described their goals for inclusion:

The biggest thing I would hope for him would be able to function in the normal classroom or extra-curricular environment without needing the assistance of an aide or to be pulled out for special classrooms. His team agrees that that is a tangible goal for him 
in the next five or ten years, to be able to be integrated into regular classwork and be able to participate in sports." -03

For this parent, and others, after aging out of EI, inclusion was one of the most important academic goals for their children. Thus, during the interview, this parent emphasized that she and the special education team were working toward achieving these goals of inclusion.

Other parents described more long-term academic goals such as transitioning their children out of public school. One parent described her goals for her child after high school:

I want him to continue with education as long as he can. We are not really sure about anything post high school, but we would like to see him graduate. We are hoping for a regular diploma instead of a modified, but he is still so young that we are not really sure what is ahead. -012

For this parent, her child's future after transitioning out of high school is still very distant and uncertain. She would like her child to pursue higher education, but is flexible and understands that this might not be the best option for him. The parent notes that at this stage, with her child being "so young," it is still early for planning goals at these later stages.

\section{Letdown After EI}

After aging out of EI services, a majority (18) of the parents described feelings of frustration with their ability to access services for their children. For many of the parents, transitioning from EI, where all of the services were provided for their children in home and they were given regular guidance on strategies and services for their children, to public school was a difficult transition. One parent described their experience after aging out of EI saying that "They weren't going to just offer up these services [speech, occupational therapy, physical therapy]...I felt frustrated that wasn't just assumed... since he had just come out of full-time OT with Birth 
to Three (02)." Parents described frustration in three main areas: a significant lag in time in which their children did not receive specific services, a need to acquire private therapy, and a reliance of self-education and the larger parent community to understand their children's legal rights and services.

Private therapy. During their interviews, seven parents also mentioned the need to seek private therapy services. The majority of these parents sought private therapy because they felt that adequate services were not available and/or being provided to their children in the public school setting. One such parent described that they needed to "seek [ABA] privately, because they do not offer it in the school system. There are just not enough providers in the area to offer it in the school system" (013). Unfortunately, parents also encountered issues in accessing private therapy for their children. Parents faced two primary challenges in accessing private therapy: a lack of services or service providers in a certain geographic region and issues with insurance coverage.

For some parents, insurance issues presented an issue in gaining access to private therapy. Insurances either did not cover certain services at all, required extensive assessments to access coverage, or only covered a very limited amount of therapy sessions. One parent described frustration with her insurance's requirements on evaluations in order to cover speech therapy:

The insurance will only cover [speech therapy] if she has an ear, nose, and throat [evaluation]. And, at the time, she couldn't do the hearing test because she couldn't talk. And they are like, 'What side is it coming from?' and she would kind of look this way and that way, and I don't even think she did that. So we ended up not doing the speech now. -01 
For this parent, and others, issues with insurance coverage ultimately led to their children not receiving one or more services. Although many of the parents in the study were of middle income ( $M=\$ 68,000$ annually), the cost of paying for services out of pocket was still too expensive for many parents; thus, without insurance coverage, their children could not receive services. If services were not provided in the public school setting, many children were not receiving any services at the time.

Other parents also described issues with finding private therapy providers in their geographic areas. One parent described her experience accessing behavioral services, "It took us a while to get in because there aren't very many people who do ABA in [city name], and we had to wait to get evaluated. (02)" Accessing private therapy in some of the more remote, rural areas was an issue for several parents. And, in several of these areas, there were no or few providers for specific services (e.g., speech, behavior, occupational therapy, speech therapy) available in the school system; thus, the availability of these services was extremely limited in both settings, private and public.

Lag in services. Several parents $(n=13)$ described that upon aging out of EI, there was a significant time period in which they did not receive specific services (e.g., occupational therapy, speech therapy, physical therapy, special education, behavioral therapy) that they previously received in EI. Three primary themes emerged within this category that caused a lag in specific services for children: issues with accuracy of evaluations, issues with availability of services and service providers in certain geographic regions, and issues with insurance coverage for services.

Parents expressed frustration that services they previously received in EI did not automatically continue upon transitioning into public school. Some specific services were either not available in the public school setting at all, or parents felt frustrated with the frequency at 
which they were receiving those services. As one parent described, "We went without speech for a while [after entering the public school]...[now] just once a week for 30 minutes...I don't know how valuable it is going to be. I wish there was more speech involved" (013).

Other parents expressed frustration that their children were receiving little to no services due to issues with schools not recognizing their children's disability diagnosis. For instance, one parent described that her child did not "receive any services. He doesn't have an IEP. Even though he has an autism diagnosis, they say he doesn't qualify for services and they won't give him an IEP (015).”

For other parents it was difficult to even get into public school immediately after aging out of EI (age 3). In order to get into public school, their children had to meet certain assessment criteria, and some of the parents questioned the accuracy of these assessments. One parent described issues getting her child into preschool at age 3 and struggling with evaluations to get her child to qualify:

They knew something wasn't right so we had [EI] until she was 3 and tried to get her into the public school system to have her start early, but she didn't qualify at preschool because she didn't have 2 different areas of delay... Because she does better in school, she doesn't qualify for services. -010

After a significant length of time in which their children were not receiving one or more services in the public school, some parents had to seek legal action. These parents expressed extremely high levels of frustration in their transition out of EI into public school. As a result of these frustrations, parents took it upon themselves to take legal steps to advocate for their children and get them the services they were legally entitled. One such parent described her 
experience in accessing services for her child in the public school setting, and taking legal action to gain these services and accommodations:

He went into kindergarten after two years of preschool and having the services...He had a terrible time with the teacher... I ended up taking the district to mediation because he did not progress at all that year and the school district agreed to transfer him to another classroom and give him the supports... During that next time period he was given the iPad all day, everyday. I took them to mediation again and got extended school year for the instructional time that I missed. - 016 Geographic region was another issue for parents that contributed to a lag in services. Much of the state of West Virginia is rural with mountainous terrain. In some of the more remote, rural areas, specific services may not be available at all or, if available, there are very few qualified service providers. These issues with accessing private therapies are only exacerbated by the fact that some parents are also having issues with accessing services in the public school setting. One parent described their experience not being able to easily access behavioral services, speech therapy, or occupational therapy for their child after aging out of EI. In this parents' experience, accessing services was challenging as a result of both a lack of services in their region and insurance issues:

ABA Therapy is a huge issue in the state, especially the southern part. It was really hard to get him in it because of insurance issues. Secondly, there isn't anybody around here... Speech therapy has been a nightmare for my insurance because they don't understand that my son is nonverbal. And occupational therapy, I have only found one person in the area, and I have not gotten a response from them. And occupational therapy is what got 
him ready to speak. If his sensory needs are met, he is able to try to communicate and learn more. - 20

Reliance on self-education and parent community. The majority of the parents interviewed $(n=15)$ expressed having to rely on self-education and the larger community of parents of children with disabilities to understand what services are available and their legal rights upon transitioning to public school. For several parents this was frustrating because "with Birth to Three, we had someone whose sole job was to tell me all the cool services they could do with him, and now I have to research that on my own" (09). This transition from being in EI, where they had someone whose role was to guide parents in advocating and understanding their children's rights to having to do this research independently, was challenging for many parents.

Parents had very little assistance in understanding the services available in public school. Several parents described having to educate themselves on their legal rights in order to be able to advocate for their children because, after EI, no one who taught them about their children's legal rights and the appropriate steps to advocate. One parent described their experience with the public school saying that they had to educate themselves on public policies and their legal rights in order to gain behavioral services for their child:

In Pre-K I had to pick up the policy 24-19 and learn it because there was an incident where he actually went out of the classroom for 14 minutes and nobody knew where he was, and the school reported it to me so I had to get a legal advocate and set the precedent for how it was going to go throughout his educational career... I want him to get services, all the services. At that point, after the advocate, they brought in a behavioral specialist to work with him, and that carried on. To this day, he still has 4 hours and 45 minutes with the behavior specialist. But I had to take the county board to mediation. -016 
Other parents described the need to rely on the larger community of other parents of children with disabilities to understand their legal rights and potential legal procedures to gain access to necessary services because professionals in the public school setting were not providing this information and assistance. For instance, one parent described how she has helped other parents through the process:

People ask me, 'But where do I start?' And I am like, ‘Get every handbook available. Read it front to back. Know what services are available to you because they really won't tell you and they're like that isn't available, but then this page right here says that you can.'

This parent described that there are few professional advocates available to parents in the public school setting. Thus, this parent, and others have relied on each other for support in understanding the process of gaining access to services in the public school setting.

As the parents in this category described, there were very few professionals in the public school system that helped them through this transition process. One parent described their feelings after aging out of EI: "We struggled with the unknown. After she turns 3, this is over. ... As a parent, it is like, couldn't it be birth to five? This is great. Can we just continue this?" (017). These feelings or being lost after EI were only exacerbated by the fact that there were few professionals in the public school system who helped parents advocate for their children. However, this did not deter the parents in the interviews from advocating for their children. Parents took it upon themselves to find the resources necessary to educate themselves on the available services and their children's rights. Parents also described helping other parents of children with disabilities understand their legal rights in order to help them better advocate for 
their children. This aspect of community seemed to be very beneficial to some parents, and helped ease the transition process into public school. 


\section{Chapter V}

\section{Discussion}

The goal of this study was to understand how parents perceive their goals, involvement, satisfaction, and transition into and out of EI. Parents described their experiences in three phases: before EI, during EI, and after EI (see Figure 1). Before EI, parents expressed high levels of frustration with gaining a referral and access to EI. Once parents were in EI, their feelings shifted to high levels of satisfaction with EI and their level of collaboration with service providers. However, once children aged out of EI, parents' perceptions shifted once again, with parents describing extremely high levels of frustration with their access to services in the public school setting. Parents also described their goals for their children in three phases: before, during, and after EI. Within each of these phases, development in language/communication and social settings were primary goals for parents.

\section{Theoretical Model and Propositions}

This study utilized GTM to develop a theory to better understand the experiences of parents of children with ASD in EI. Specifically, how do parents perceive their involvement, satisfaction, goals, and transition into and out of EI? The interviews were analyzed and a stage theory was developed. Specific theoretical propositions are described below:

1. Prior to entering EI, parents experienced a number of barriers (e.g., pediatricians not referring) that limited their access to EI.

2. While children were in EI, parents experienced high levels of collaboration between family members and service providers. 
3. As a result of high levels of professional skill, collaboration, and trust between parents and service providers, children were able to make significant progress toward their goals during EI.

4. After aging out of EI, parents expressed feeling lost and having very little guidance from professionals in helping them understand the process and procedures to gain access to services in the public school setting.

5. Parental agency was critical to parents gaining access to early intervention and understanding and gaining access to services after EI within the public school setting, with several parents researching services and legal rights independently and/or helping other parents of children with ASD understand available services and their legal rights.

6. Throughout each phase in the model, social and language/communication were the primary focus of parents' goals for their children. 


\section{Parent Involvement and Satisfaction}

The first research question this study sought to answer focused on parents' perceptions of their involvement in EI. In the interviews, parents were asked questions about their involvement during EI in relation to home visits, activities, and goal planning. Parents described high levels of involvement in activities. Parents felt that service providers collaborated with them in planning goals and in conducting activities to promote their children's development. Parents also noted that service providers involved their children and extended family members in their activities. Service providers also spent time teaching parents about parenting strategies (e.g., behavioral management techniques) and their children's disability. Parents expressed appreciation that service providers not only focused on their children's development, but also on parent education.

The second research question of this study focused on understanding how parents perceive their satisfaction in EI. In the interviews, parents expressed high levels of satisfaction with EI. Parents described highly skilled service providers who were flexible in their activities and focused on educating the family in addition to promoting children's development. Because of the high level of skill service providers exhibited and the high levels of collaboration and trust between parents and providers, children were able to make significant progress toward their goals during EI. These high levels of child progress also led to high levels of satisfaction among parents.

Parents are a critical component to interventions, and when parents serve as co- or primary-intervention agents, studies indicate more positive child and family outcomes (Dempsey \& Keen, 2008; Dunst et al., 2007; McConachie \& Diggle, 2006). When parents are highly involved and service providers collaborate effectively with them, parents express a higher level of satisfaction. Past qualitative research on EI outcomes indicates that parents were highly 
dissatisfied with certain aspects of EI, particularly the lack of individualization and provider training related to ASD (e.g., Coogle et al., 2013), and a lack of focus on skills related to emotional competence (e.g.,Whittingham et al., 2009). The current study did not find high levels of dissatisfaction with EI, with only a couple of parents $(n=4)$ expressing any specific areas of dissatisfaction. On the contrary, parents in this study described a high level of satisfaction with the level of individualization, collaboration, and trust between providers and family members, and reported high levels of child progress, as a result. Thus, for the parents of this study, high levels of collaboration and trust between providers and family members resulted in parents feeling high levels of satisfaction with EI services. The experiences of the parents in this study support past research (e.g., Dempsey \& Keen, 2008; Dunst et al., 2007; McConachie \& Diggle, 2006) findings that when service providers work with parents to collaborate on goal planning and activities, parents feel more satisfied with the level of individualization they are receiving in their EI services and children and families have better outcomes.

It is important to note that although the findings of this study on parental satisfaction are different than previous studies, all families have unique experiences and challenges. The findings of this study do lend support to the importance of family-centered intervention as has been found in previous research (Dempsey \& Keen, 2008; Dunst et al., 2007; McConachie \& Diggle, 2006). In previous studies (e.g., Whittingham et al., 2009; Coogle et al., 2013), parents felt lower levels of satisfaction with interventions as a result of a lack of individualization and collaboration between service providers and family members. It is possible that in studies past service providers did not have adequate training in collaboration and individualization; thus, resulting in lower levels of collaboration and individualization and, as a result, lower parental satisfaction and poorer family and child outcomes. In the current study, parents felt that they were highly 
involved and that service providers were highly skilled and collaborated with them throughout EI, thus resulting in high levels of satisfaction and child progress. Thus, in each of these studies the family-centered intervention model is key to parental satisfaction and positive child outcomes. Given the importance of collaboration and the family-centered model of EI in predicting parental satisfaction and child outcomes, it is critical that adequate training be provided to instruct EI providers in effective collaboration techniques.

\section{Parent Goals}

Parents described their goals in accordance with the theoretical model proposed in this study: before, during, and after EI. Before EI, parents mentioned goals that were related to areas of delay in their children and noted these goals for their children's development as their rationale for seeking EI. During EI, parents described the specific goals the service provider and parents were working with children on throughout EI. After aging out of EI, parents described both short- and long-term goals.

Another research question in this study focused on understanding parents' goals for their children. Specifically, there is little research focused on understanding parents' goals for their children's socio-emotional development and how their children's progress on these goals influence their satisfaction. Understanding these socio-emotional goals and how these goals influence parental satisfaction was a primary focus of this study. The parents in this study described language/communication and social goals as their primary focus for their children's development throughout each of the phases: before, during, and after EI. Parents also perceived clear connections between their children's progress in language/communication and their behavior and social skills. Although it was an interest on the part of the researcher, and previous research indicates a clear connection between emotional development and children's social skills 
(Baker et al., 2011; Gross et al., 2015; Pouw et al., 2013) parents did explicitly mention emotional goals for their children. However, many of the issues that parents mentioned in their interviews were both emotional and behavioral in nature (e.g., meltdowns). Thus, there was a connection to emotional goals even though parents did not note that their goals were for their children's emotional development. Parents focused on how improvements in language and communication would impact their children's behavioral and social development. This focus on behavior and social skills makes sense as both behavioral issues (e.g., tantrums/meltdowns and aggression) and challenges in social situations were mentioned as some of the areas their children struggled. Behaviors are also more easily observable than are emotions; thus, a connection between behavior and emotions and/or emotional and social skills may not have been mentioned as frequently by parents because it not easily observed. Moreover, some of the children in the study were nonverbal or had limited verbal communication skills, making it more difficult for them to communicate their feelings with their parents; thus, feelings such as anger are observed through behaviors (e.g., meltdowns).

The findings of this study suggest that parents have a strong focus on improving the language and communication skills of their children, and that they believe that through improving language and communication this will ultimately have a positive effect on their children's behavior and social skills. This was the case for several of the parents in the current study that noted that during EI improvements toward their children's goals in language and communication had a direct impact on their children's behavior and social skills. These findings indicate that EI service providers should focus on improving the language and communication skills of children with ASD, and that improving language and communication may ultimately have a positive impact on behavior (e.g., a reduction in meltdowns) and social skills. 


\section{Transition into and out of EI}

The final research question of this study focused on understanding parents' perceptions of their transition into and out of EI. In both phases parents expressed high levels of frustration in their access to services and parental agency was critical to gaining access to these services. Prior to EI, parents expressed high levels of frustration with pediatricians not referring. Pediatricians did not share the same concerns as children's parents, and as a result did not refer them for EI services. These issues with referral delayed the start of services and reduced the amount of time in which children were able to benefit from being involved in EI services. After doing their own research and/or consulting with the community of other parents of children with disabilities, several parents ended up self-referring to EI. After EI, parents expressed feeling let down. They went from having a very high level of social support during EI from their service providers, to feeling like the had little to no support in the public school setting. Parents were also not satisfied with the number of services or service frequency provided in the public school setting. Again, parental agency and the larger community of parents of children with disabilities were critical in helping parents understand the services available and their legal rights in the public school.

Parenting children with disabilities and trying to help them access necessary services can be extremely stressful (Myers et al., 2009; Woodgate et al., 2011). Parents of children with ASD often experience significant social isolation, particularly in the public school setting, and often have to fight to get their children the services they need (Gill \& Liamputtong, 2011; Woodgate et al., 2011). In accordance with Hill's $(1949,1958)$ ABC-X model, family stress can lead to crisis if parents do not have access to social resources and perceive the stressor to be insurmountable. Prior to entering EI, parents had limited social resources to assist them in parenting their children with ASD, and pediatricians and other family members were not always supportive about their 
referral into EI. Parents relied on self education and other parents in the ASD community to find EI programs and self-referred. During EI, parents perceived a high level of social support from their EI service providers; however, after entering EI, this support was extremely limited in the public school setting. Again, parents relied on their own self education and parents in the ASD community to understand available services and legal rights. Both prior to EI and after EI, parents were able to lean on parents in the ASD community for support. This social support was critical in helping these parents gain access to services for their children. Moreover, this social support may have been an important factor in adjusting their perception of parenting children with ASD and preventing a potential crisis level of stress (Hill, 1949, 1958).

The findings on transition into and out of EI suggest that parenting support programs and initiatives are needed. Prior to EI, a number of parents noted that their pediatricians did not express concerns for their children's development or refer to EI even when their child was clearly exhibiting developmental delays. Further training for pediatricians and other medical professionals may be needed to help identify children with delays and disabilities. Simply educating medical professionals is not enough. Parental education initiatives and programs are also needed. Some of the parents did not know about EI or about their ability to self refer. Initiatives and programs should be created to help educate and inform parents about the availability of such programs. In addition, more Child Find programs are needed to help identify and get infants and toddlers with delays into EI. Child Find programs are government-mandated initiatives providing free assessments to identify infants and toddlers with disabilities who may require EI services. These programs have been shown to be effective at increasing the number of children with delays and disabilities who are identified and enrolled in EI (Holland \& Merrell, 
1998; Macy, Marks, \& Towle, 2014). Prior research indicates that being in EI for a longer period of time is related to improved child outcomes (Macy et al., 2014).

After EI, again parents had little support in advocating for their children. They felt that while in EI, there were multiple individuals whose role was to help them understand their children's rights and needs and teach them to advocate for their children. After EI, this support was lost. After EI, several parents had difficulty obtaining services for their children (e.g., special education, physical therapy, speech therapy) who had previously qualified for EI. Many parents specifically stated that they wished that EI could be extended to a later age (i.e., beyond age 3). The results of this study are similar to the transition experiences described in prior studies (Burke 2013; Fish, 2008; Kalyanpur, Harry, \& Skrtic, 2000; Stoner et al., 2005). In past studies, parents described feelings of intimidation and a lack of understanding of the special education system as barriers to their involvement. And, as a result of these barriers, parents did not feel they could be highly involved in IEP meetings and in their children's overall special education programs (Hess, Molina, \& Kozleski, 2006; Munn-Joseph \& Gavin-Evans, 2008).

It is critical that resources and programs be created to support parents beyond infancy in advocating for their children. During EI, the family-centered model is highly effective in improving both family and child outcomes. It is important that parents continue to be involved and educated on interventions beyond infancy, into childhood and beyond. Parents and the family unit continue to serve an important role throughout children's lives; thus, support programs should not end at age 3 . There is research indicating that parental advocacy programs can be effective at improving parental participation and parents' overall satisfaction in special education within the public school setting (Burke, 2013; Wheeler \& Marshall, 2008). When special education advocates are trained to provide support, education, and advocacy training to 
parents of children with special needs, parents feel more comfortable and confident participating in special education programs (Burke, 2013; Wheeler \& Marshall, 2008). Importantly, research indicates that beyond EI, and into primary and secondary school, parental involvement continues to be critical to child outcomes, and should be a focus of special education programs (Burke, 2013; Green, Walker, Hoover-Dempsey, \& Sandler, 2007). Similar child advocacy programs should be formed on a larger scale in West Virginia and other states, and longitudinal experimental and longitudinal mixed-methods designs should be employed to test the effectiveness of these child advocacy programs.

Future research should focus on understanding how parents can best be supported during this transition out of EI and into public school. Further quantitative study is needed to understand if the findings of the current study are generalizable to a larger population. Are the negative experiences and letdown after aging out of EI and entering public school common or are they unique to the parents of this study? Longitudinal design studies are necessary to understand the experiences of parents transitioning out of EI and into primary and secondary school. If these negative experiences after aging out of EI and entering the public school are common, mixedmethod and experimental design research is needed to understand how to best support parents and their children after aging out of EI and entering the public school setting.

\section{Limitations and Future Directions}

This study has a few notable limitations. First, only parents who saw the advertisements and selected to contact us were scheduled to conduct interviews. Thus, we were limited to parents who had access to internet and/or who saw our physical advertisements. Second, only one of the 20 participants was a father. The experiences of the parents described in this study may be more representative of mothers than fathers. Fathers were not excluded from the study, 
but only one father expressed interest in the study. Research suggests that fathers are an important aspect of the family centered model of EI, and that fathers may serve a unique role in EI, influencing different aspects of child outcomes than do mothers (Flippin \& Crais, 2011; Flouri \& Buchanan, 2004; Roggman, Boyce, Cook, \& Cook, 2002). Thus, in order to get a complete picture of the experiences of families in EI, both fathers and mothers should be included. In the future, conducting a similar study with fathers would be worthwhile.

Future research should focus on better understanding why parents have such a negative experience transitioning into and out of EI. Both quantitative and qualitative research is necessary to understand how to best identify and get children into EI so that they may have a longer duration of services in EI. Quantitative study is necessary to understand if the negative experiences of the parents in the current study post EI are common or unique to this study. Mixed-methods and experimental design research is needed to develop programs to support parents of children with ASD in advocating for their children's needs after aging out of EI. Understanding the experiences of fathers should be another focus of future qualitative research. Past research indicates that fathers have an important role in EI, and make unique contributions to children's short and long-term outcomes of children after EI (Flippin \& Crais, 2011; Flouri \& Buchanan, 2004; Roggman et al., 2002). Only one father was involved in the current study; thus, the experiences of the participants are more representative of mothers. It is important to understand how fathers feel about their goals, involvement and satisfaction in EI. Do fathers have a similar experience to mothers? Are they satisfied with their level of involvement and collaboration during EI? Do they follow the three-phase model described in the theory: frustration with referral into EI, satisfaction with collaboration and involvement during EI, and frustration with access to services after EI? If fathers face significant challenges in 
accessing services prior to and after EI, further quantitative research is necessary to understand how to best support fathers during these times of transition. Longitudinal experimental designs should be employed to understand if the parental advocacy programs which have been shown to be effective in improving parental involvement in primary and secondary school special education programs are also effective at improving the involvement of fathers, as the majority of the research on parental participation in special education during primary and secondary school utilize predominately mother samples (Flippin \& Crais, 2011).

Another focus of future research should be on understanding the EI experiences of lower income families of children with ASD. Most of the parents in the current study were of higher socioeconomic status (annual income, $M=\$ 68,000$; some college, $n=8$; college degree, $n=9$; graduate degree, $n=3$ ). The social resources of parents who are lower income may be significantly different from those of middle incomes. Parents of different income and educational levels may also have different levels of satisfaction with EI and/or may have different experiences with involvement. They may also have different perceptions of their transitions into EI and transition out of EI and into public school. Mixed-method studies should be conducted to understand the EI outcomes, EI satisfaction, and transition experiences of lower income families.

\section{Conclusion}

The purpose of this study was to understand parents of children with ASD's perceptions of their goals for their children's development, involvement, satisfaction, and transition into and out of EI. Contradictory to prior studies, parents of the current study expressed very high levels of overall satisfaction during EI, citing high levels of involvement and collaboration with parents and individualization in goals focused on child and family needs, resulting in high levels of child progress. These findings suggest that collaboration and parental involvement are critical to 
family and child outcomes, and training service providers on collaboration and the familycentered model of EI is imperative. In the phases prior to and after EI, parents felt extremely high levels of frustration in gaining access to services and extremely low levels of parental support. The experiences of these parents highlight a need for future research focused on the development of programs to support parents during the years of transition into and out of EI. 


\section{References}

Baio, J. (2014). Developmental Disabilities Monitoring Center, U.S. Center for Disease Control and Preventation. Prevalence of spectrum disorder among children aged 8 years. Washington, DC: U.S. Printing Center.

Baker, J. K., Fenning, R. M., \& Crnic, K. A. (2011). Emotion socialization by mothers and fathers: Coherence among behaviors and associations with parent attitudes and children's social competence. Social Development, 20(2), 412-430. doi: 10.1111/j.14679507.2010.00585.x

Baron-Cohen, S., Golan, O., \& Ashwin, E. (2009). Can emotion recognition be taught to children with autism spectrum conditions?. Philosophical Transactions of the Royal Society B: Biological Sciences, 364(1535), 3567-3574. doi: 10.1098/rstb.2009.0191

Baurain, C., \& Nader-Grosbois, N. (2013). Theory of mind, socio-emotional problem-solving, socio-emotional regulation in children with intellectual disability and in typically developing children. Journal of Autism and Developmental Disorders, 43(5), 1080-1097. doi: $10.1007 /$ s10803-012-1651-4

Bougher-Muckian, H. R., Coogle, C. G, Floyd, K., \& Root, A. (2018). Parent perceived early intervention outcomes and helpfulness based upon disability category. Manuscript in press for Scholar Practitioner Quarterly.

Bougher-Muckian, H. R., Root, A., Coogle, C. G., \& Floyd, K. (2016). The importance of emotions: The socialisation of emotion in parents of children with autism spectrum disorder. Early Child Development and Care, 186, 1584-1593.doi:

$10.1080 / 03004430.2015 .1112799$ 
Bougher-Muckian, H. R., Root, A., Floyd, K., Coogle, C. G., \& Hartman, S. (2017). The association between adaptive functioning and parents' attributions for children's emotions. Early Child Development and Care. In press. doi:

$10.1080 / 03004430.2017 .1396979$

Brown, M. A., McIntyre, L. L., Crnic, K. A., Baker, B. L., \& Blacher, J. (2011). Preschool children with and without developmental delay: Risk, parenting, and child demandingness. Journal of Mental Health Research in Intellectual Disabilities, 4(3), 206-226. doi: 10.1080/19315864.2011.596990

Brown, W. H. \& Conroy, M. A. (2011). Social-emotional competence in young children with developmental delays our reflection and vision for the future. Journal of Early Intervention, 33(1), 310-320. doi: 10.1177/1053815111429969

Brownell, C. A., Svetlova, M., Anderson, R., Nichols, S. R., \& Drummond, J. (2013). Socialization of early prosocial behavior: Parents' talk about emotions is associated with sharing and helping in toddlers. Infancy, 18(1), 91-119. doi: 10.1111/j.15327078.2012.00125.x

Bruder, M. B. (2000). Family-centered early intervention: Clarifying our values for the new millennium. Topics in Early Childhood Special Education, 20(2), 105-115. doi: $10.1177 / 027112140002000206$

Burke, M. B. (2013). Improving parental involvement: Training special education advocates. Journal of Disability Policy Studies, 23(4), 225-234. doi: 10.1177/1044207311424910

Centers for Disease Control and Prevention. (2014). Autism Spectrum Disorder. Data and Statistics. Retrieved from http://www.cdc.gov/ncbddd/autism/data.html 
Cole, P. M., Dennis, T. A., Smith-Simon, K. E., \& Cohen, L. H. (2009). Preschoolers' emotion regulation strategy understanding: Relations with emotion Socialization and child selfregulation. Social Development, 18(2), 324-352. doi: 10.1111/j.1467-9507.2008.00503.x

Collins, W. A., Maccoby, E. E., Steinberg, L., Hetherington, E. M., \& Bornstein, M. H. (2000). Contemporary research on parenting: The case for nature and nurture. American Psychologist, 55(2), 218. doi:10.1037/0003-066X.55.2.218

Coogle, C. G., Guerette, A., \& Hanline, M. F. (2013). Early intervention experiences of families of children with an autism spectrum disorder: A qualitative pilot study. Early Childhood Research and Practice, 15, n.p.

Creswell, J. W. (1998). Qualitative Inquiry and Research Design Choosing among five traditions Sage: London.

Davis, E. L., \& Buss, K. A. (2012). Moderators of the relation between shyness and behavior with peers: Cortisol dysregulation and maternal emotion socialization. Social Development, 21(4), 801-820. doi: 10.1111/j.1467-9507.2011.00654.x

Dempsey, I., \& Keen, D. (2008). A Review of processes and outcomes in family-centered services for children with a disability. Topics in Early Childhood Special Education, 28(1), 42-52. doi: 10.1177/0271121408316699

Denham, S. A., Bassett, H. H., \& Wyatt, T. (2007). The socialization of emotional competence. In Grusec, J.E. \& Hastings, P. D. (Eds), Handbook of socialization: Theory and research (614-637). New York: Guilford.

Denham, S. A., Bassett, H. H., \& Zinsser, K. (2012). Early childhood teachers as socializers of young children's emotional competence. Early Childhood Education Journal, 40(3), 137143. doi: $10.1007 / \mathrm{s} 10643-012-0504-2$ 
Denham, S., \& Kochanoff, A. T. (2002). Parental contributions to preschoolers' understanding of emotion. Marriage and Family Review, 34(3-4), 311-343. doi: 10.1300/J002v34n03_06

Denham, Susanne, Blair, K. A., DeMulder, E., Levitas, J., Sawyer, K., Auerbach-Major, S., Queenan, P. (2003). Preschool emotional competence: Pathway to social competence? Child Development, 74, 238-256. doi: 10.1111/1467-8624.00533

Dunst, C.J., Hamby, D.W., \& Brookfield, J. (2007). Modeling the effects of early childhood intervention variables on parent and family well-being. Journal of Applied Quantitative Methods, 2(3), 268-288. doi: 10.1177/027112140002000205

Eisenberg, N., Cumberland, A., \& Spinrad, T. L. (1998). Parental socialization of emotion. Psychological Inquiry, 9(4), 241-273. doi: 10.1207/s15327965pli0904_1

Eisenberg, N., \& Fabes, R. A. (1994). Mothers' reactions to children's negative emotions: Relations to children's temperament and anger behavior. Merrill-Palmer Quarterly, 40(1), 138-156. doi: 10.1002/dev.20608

Eisenberg, N., Valiente, C., Sheffield Morris, A., Fabes, R., Cumberland, A., Reiser, M., Gershoff, E., Shepard, S., \& Losoya, S. (2003). Longitudinal relations among parental emotional expressivity, children's regulation, and quality of socioemotional functioning. Developmental Psychology, 39(1), 3-19. doi: 10.1037/0012-1649_39.1.3

Epley, P. H., Summers, J. A., \& Turnbull, A. P. (2011). Family outcomes of early intervention: Families' perceptions of need, services, and outcomes. Journal of Early Intervention, 33(3), 201-219. doi: 10.1177/1053815111425929

Farrell, A. F. (2009). Validating family-centeredness in early intervention evaluation reports. Infants \& Young Children, 22(4), 238-252. doi: 10.1191/0269215506cr979oa

Fish, W. W. (2008). The IEP meeting: Perceptions of parents of students who receive special 
education services. Preventing School Failure, 53, 8-14. doi: 10.3200/PSFL.53.1.8-14

Flippin, M., \& Crais, E. R. (2011). The need for more effective father involvement in early autism intervention: A systematic review and reccomendations. Journal of Early Intervention, 33, 24-50. doi: 10.1177/1053815111400415

Flouri, E., \& Buchanan, A. (2004). Early father's and mother's involvement and child's later educational outcomes. British Journal of Educational Psychology, 74(2), 141-153. doi: $10.1348 / 000709904773839806$

Garner, P. W., Dunsmore, J. C., \& Southam-Gerrow, M. (2008). Mother-child conversations about emotions: Linkages to child aggression and prosocial behavior. Social Development, 17(2), 259-277. doi: 10.1111/j.1467-9507.2007.00424

Garner, P. W., \& Estep, K. M. (2001). Emotional competence, emotion socialization, and young children's peer-related social competence. Early Education and Development, 12, 29-48. doi: 10.1207/s15566935eed1201_3

Gill, J. \& Liamputtong, P. (2011). Being a mother of a child with Asperger's Syndrome: Women's experiences of stigma. Health Care for Women International, 32, 708-722. doi: 10.1080/07399332.2011.555830.

Glaser, B., \& Strauss, A. (1967). The discovery of grounded theory. 1967. Weidenfield \& Nicolson, London, 1-19.

Green, C. L., Walker, J. M. T., Hoover-Dempsey, K. V., \& Sandler, H. M. (2007). Parents' motivations for educational involvement in children's education: An empirical test of a theoretical model of parental involvement. Journal of Educational Psychology, 99(3), 532-544. doi:10.1037/0022-0663.99.3.532 
Gross, R. L., Drummond, J., Satlof-Bedrick, E., Waugh, W. E., Svetlova, M., \& Brownell, C. A. (2015). Individual differences in toddlers' social understanding and prosocial behavior: disposition or socialization?. Frontiers in Psychology, 6. doi:10.3389/fpsyg.2015.00600

Green-Emrich, A. \& Altmaier, E. M. (1991). Attribution retraining as a structured group counseling intervention. Journal of Counseling \& Development, 69(4), 351-355. doi: 0.1002/j.1556-6676.1991.tb01520

Hastings, R. P., \& Brown, T. (2002). Behavior problems of children with autism, parental selfefficacy, and mental health. American journal on mental retardation, 107(3), 222-232. doi: 10.1352/0895-8017(2002)107<0222:BPOCWA>2.0.CO;2

Havighurst, S. S., Wilson, K. R., Harley, A. E., Prior, M. R., \& Kehoe, C. (2010). Tuning in to Kids: improving emotion socialization practices in parents of preschool children-findings from a community trial. Journal of Child Psychology and Psychiatry, 51(12), 1342-1350. doi: $10.1111 / \mathrm{j} .1469-7610.2010 .02303 . x$

Haynes, T. L., Perry, R. P., Stupnisky, R. H., \& Daniels, L. M. (2009). A review of attributional retraining treatments: Fostering engagement and persistence in vulnerable college students. In Higher education: Handbook of theory and research (pp. 227-272). Springer Netherlands.

Haynes, T. L., Ruthig, J. C., Perry, R. P., Stupnisky, R. H., \& Hall, N. C. (2006). Reducing the academic risks of over-optimism: The longitudinal effects of attributional retraining on cognition and achievement. Research in Higher Education, 47(7), 755. doi:

$10.1007 / \mathrm{s} 11162-006-9014-7$ 
Hess, R. S., Molina, A. M., \& Kozleski, E. B. (2006). Until somebody hears me: Parent voice and advocacy in special education decision making. British Journal of Special Education, 33(4), 148-157. doi: 10.1111/j.1467-8578.2006.00430.x

Hill, R. (1949). Families under stress: Adjustment to the crises of war separation and reunion. New York, Harper \& Brothers [1949].

Holland, M. L., \& Merrell, K. W. (1998).Social-emotional characteristics of preschool-aged children referred for child find screening and assessment: A comparative study. Research in Developmental Disabilities, 19(2), 167-179. doi: 10.1016/S0891-4222(97)00049-8

Jones, S., Eisenberg, N., Fabes, R. A., \& MacKinnon, D. P. (2002). Parents' reactions to elementary school children's negative emotions: Relations to social and emotional functioning at school. Merill-Palmer Quarterly, 48(2), 133-159. doi: 10.1111/j.14678624.1996.tb01854.x/pdf

Kalyanpur, M., Harry, B., \& Skrtic, T. (2000). Equity and advocacy expectations of culturally diverse families' participation in special education. International Journal of Disability, Development, and Education, 47(2). doi: 10.1080/713671106

Kvale, S., \& Brinkmann, S. (2009). Interviews: Learning the craft of qualitative research. California, US: SAGE.

Leerkes, E. M., Blankson, A. N., \& O’Brien, M. (2009). Differential effects of maternal sensitivity to infant distress and nondistress on social-emotional functioning. Child Development, 80(1), 762-775. doi: 0.1111/j.1467-8624.2009.01296

Macy, M., Marks, K., \& Towle, A. (2014). Missed, misuses, or mismanaged: Improving early detection systems to optimize child outcomes. Topics in Early Childhood Special Education, 34(2), 94-105. doi: 10.1177/0271121414525997 
Mahoney, G., \& Perales, F. (2003). Using relationship-focused intervention to enhance the social—emotional functioning of young children with autism spectrum disorders. Topics in Early Childhood Special Education, 23(2), 74-86. doi:

$0.1177 / 02711214030230020301$

McConachie, H., \& Diggle, T. (2006). Parent implemented early intervention for young children with autism spectrum disorder: A systematic review. Journal of Evaluation in Clinical Practice, 13(1), 120-129. doi: 10.1111/j.1365-2753.2006.00674

McCubbin, H. I., \& Patterson, J. M. (1983). The family stress process: The double ABCX model of adjustment and adaptation. Marriage \& Family Review, 6(1-2), 7-37. doi: 10.1300/J002v06n01_02

Morgan, D. L. (1996). Focus groups as qualitative research (Vol. 16). Sage publications.

Morris, C. A., Denham, S. A., Bassett, H. H., \& Curby, T. W. (2013). Relations among teachers' emotion socialization beliefs and practices and preschoolers' emotional competence. Early Education \& Development, 24(7), 979-999. doi:10.1080/10409289.2013.825186

Munn-Joseph, M. S. \& Gavin-Evans, K. (2008). Urban parents of children with special needs: Advocating for their children through social networks. Urban Education, 43(3), 378-393. doi: $10.1177 / 0042085907311803$

Myers, B. J., Mackintosh, V. H., \& Goin-Kochel, R. P. (2009), “My greatest joy and my greatest heart ache:" Parents' own words on how having a child in the autism spectrum has affected their lives and their families' lives. Research in Autism Spectrum Disorders, 3, 670-684. doi: 10.1016/j.rasd.2009.01.004

O'Donoghue, T., \& Punch, K. (Eds.). (2003). Qualitative educational research in action: Doing and reflecting. Routledge. 
Perlman, S. B., Camras, L. A., \& Pelphrey, K. A. (2008). Physiology and functioning: Parents' vagal tone, emotion socialization, and children's emotion knowledge. Journal of Experimental Child Psychology, 100(4), 308-315. doi: 10.1016/j.jecp.2008.03.007

Pouw, L, B. C., Rieffe, C., Oosterveid, P., Huskens, B., \& Stockmann, L. (2013). Reactive/proactive aggression and affective/cognitive empathy in children with ASD. Research in Developmental Disabilities, 34(4), 1256-1266. doi: 10.1016/j.ridd.2012.12.022

Roggman, L. A., Boyce, L. K., Cook, G. A., \& Cook, J. (2002). Getting dads involved: Predictors of father involvement in Early Head Start and with their children. Infant Mental Health Journal, 23, 62-78. doi:10.1002/imhj.10004

Samson, A. C., Hardan, A.Y., Podell, R. W., Phillips, J. M., \& Gross, J. J. (2015). Emotion regulation in children and adolescents with autism spectrum disorder. Autism Research, 8, 9-18. doi:10.1002/aur.1387

Samson, A. C., Phillips, J. M., Parker, K. J., Shah, S., Gross, J. J., Harden, A. Y. (2014). Emotion dysregulation and the core features of autism spectrum disorder. Journal of Autism and Developmental Disorders, 44(7), 1766-1772. doi: 10.1007/s10803-013-20225

Sheffield Morris, A., Silk, J. S., Steinberg, L., Myers, S. S. \& Robinson, L. R. (2007). The role of the family context in the development of emotion regulation. Social Development, 16(2), 361-388. doi: 10.1111/j.1467-9507.2007.00389.x

Stoner, J. B., Jones Bock, S., Thompson, J. R., Angell, M. A., Heyl, B. S., Crowley, P. (2005). Welcome to our world: Parent perceptions of interactions between parents of young 
children with ASD and education professionals. Focus on Autism and Other Developmental Disabilities, 20, 39-51. doi: 10883576050200010401

Strauss, A., \& Corbin, J. (1990). Basics of qualitative research (Vol. 15). Newbury Park, CA: Sage.

Strauss, A., \& Corbin, J. (1998). Basics of qualitative research: Procedures and techniques for developing grounded theory. Thousand Oaks: Sage.

Talay-Ongan, A. (2001). Early intervention: Critical roles of early childhood service providers. International Journal of Early Years Education, 9(3), 221-228. doi: $10.1080 / 0966976012008696$

Tanaka, J., Wolf, J., Klaiman, C., Koenig, K., Cockburn, J., Herlihy, L., Brown, C., Stahl, S., South, M., McPartland, J., Kaiser, M., \& Schultz, R. (2012). The perception and identification of facial emotions in individuals with Autism Spectrum Disorders using the Let's Face It! Emotion Skills Battery. Journal of Child Psychology and Psychiatry, and Allied Disciplines, 53(12), 1259-1267. doi: 10.1111/j.1469-7610.2012.02571.x

Taylor, Z. E., Eisenberg, N., Spinrad, T. L., Eggum, N. D., \& Sulik, M. J. (2013). The relations of ego-resiliency and emotion socialization to the development of empathy and prosocial behavior across early childhood. Emotion, 13(5), 822. doi: 10.1037/a0032894

Warren, C. A. B. (2002). Interviews as social interaction. In Gubrium, J. F., Holstein, J. A., Marvasti, A. B., \& McKinney, K. D. (Eds), The Sage Handbook of Interview Research (83-140).

Webb, S. J., Jones, E. J. H., Merkle, K., Namkung, J., Toth, K., Greenson, J., Murias, M., \& Dawson, G. (2010). Toddlers with elevated autism symptoms show slowed habituation to faces. Child Neuropsychology, 16(3), 255-278. doi: 10.1080/09297041003601454 
Wheeler, B., \& Marshall, D. (2008, March). Special education advocacy training (SEAT). Paper presented at the Council of Parent Attorneys and Advocates Conference, Anaheim, CA.

Whittingham, K., Sofronoff, K., Sheffield, J., \& Sanders, M. R. (2009). Behavioural family interventions with parents of children with ASD: What do they find useful in the parenting program Stepping Stones Triple P? Research in Autism Spectrum Disorders, 3, 702-713. doi:10.1016/j.rasd.2009.01.009

Williams, B. T., Gray, K. M., \& Tonge, B. J. (2012). Teaching emotion recognition skills to young children with autism: A randomised controlled trial of an emotion training programme. Journal of Child Psychology and Psychiatry, 53(12), 1268-1276. doi: 10.1111/j.1469-7610.2012.02593.x.

Wong, M. S., McElwain, N. L., \& Halberstadt, A. G. (2009). Parent, family, and child characteristics: associations with mother-and father-reported emotion socialization practices. Journal of Family Psychology, 23(4), 452. doi: 10.1037/a0015552.

Woodgate, R. L., Ateah, C., \& Secco, (2008). Living in a world of our own: The experience of parents who have a child with autism. Qualitative Health Research, 18, 1075-1083. doi: $10.1177 / 1049732308320112$ 
Table 1

Participant demographic characteristics

\begin{tabular}{|c|c|c|}
\hline Characteristic & $n$ & $\%$ \\
\hline \multicolumn{3}{|l|}{ Child Gender } \\
\hline Male & 17 & 85 \\
\hline \multicolumn{3}{|l|}{ Child's Race } \\
\hline White/Caucasian & 18 & 90 \\
\hline \multicolumn{3}{|l|}{ Annual Parent Income } \\
\hline Less than $\$ 10,000$ & 1 & 5 \\
\hline$\$ 10,000-\$ 25,000$ & 9 & 45 \\
\hline$\$ 25,000-\$ 50,000$ & 2 & 10 \\
\hline$\$ 50,000-\$ 75,000$ & 3 & 15 \\
\hline \multicolumn{3}{|l|}{ Parent Education } \\
\hline Some College & 8 & 40 \\
\hline College Degree & 9 & 45 \\
\hline Graduate Degree & 3 & 15 \\
\hline \multicolumn{3}{|l|}{ Parent Gender } \\
\hline Male & 1 & 5 \\
\hline Female & 19 & 95 \\
\hline
\end{tabular}


Theoretical Model of Parents of Children with ASD's Perceptions of EI

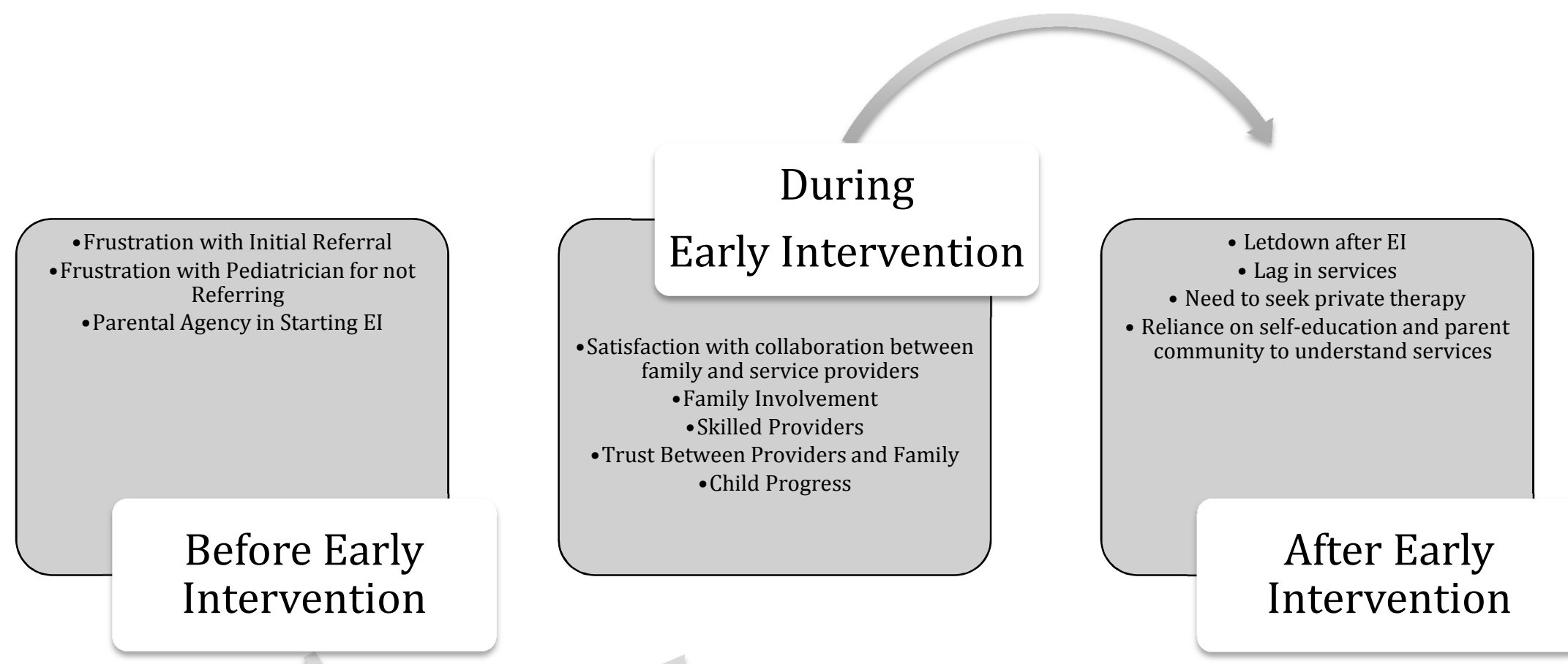




\section{APPENDIX A}

Your name:

Background/Demographics Questionnaire

What is today's date?

Your Gender:

Male

Female

Your Relation to Child:

Mother

Father

Stepmother

Stepfather

Other (please specify):

Your Age:

\section{Your Race:}

American Indian/Alaska Native

Asian

Black or African American

Middle Eastern or North African

Native Hawaiian or Other Pacific Islander

White or Caucasian

Bi- or Multi-racial (please specify):

Other (please specify):

\section{Your Ethnicity:}

Hispanic or Latino

Not Hispanic or Latino

Your Education level (please select highest level)

Elementary School

High School

Vocational School

Some College

University Degree

Some Graduate School 
Master's Degree

Doctoral Degree

\section{Your Occupation Status}

Employed full-time

Employed part-time

Not employed outside of home

Retired

Unemployed and seeking employment

Other (specify)

\section{Household Income:}

Less than $\$ 10,000$

$\$ 10,000$ - $\$ 25,000$

$\$ 25,000$ - $\$ 50,000$

$\$ 50,000-\$ 75,000$

$\$ 75,000-\$ 100,000$

$\$ 100,000-\$ 150,000$

Greater than $\$ 150,000$

Prefer not to answer

Please answer the following questions about the child you will complete the interviews about

Child's Initials:

Child's Age:

Child's Birthdate:

(Include month and year)

Child's Gender

Male

Female

\section{Child's Race:}

American Indian/Alaska Native

Asian

Black or African American

Middle Eastern or North African

Native Hawaiian or Other Pacific Islander 
White or Caucasian

Bi- or Multi-racial (please specify):

Other (please specify):

\section{Child's Ethnicity:}

Hispanic or Latino

Not Hispanic or Latino

\section{Child's biological relation to you:}

Biological

Adopted

Foster

Other, please specify:

\section{Is your child a twin?}

Yes

No

If yes, identical or fraternal?

What is the last grade your child completed in school?
Preschool
Kindergarten
$1^{\text {st }}$
$2^{\text {nd }}$
$3^{\text {rd }}$
$4^{\text {th }}$
$5^{\text {th }}$
$6^{\text {th }}$
Other:
Preschool
Kindergarten
$1^{\text {st }}$
$2^{\text {nd }}$
$3^{\text {rd }}$
$4^{\text {th }}$

What grade is your child currently enrolled? 
$5^{\text {th }}$

$6^{\text {th }}$

Other:

Is s/he currently enrolled in:

Private Preschool

Public Preschool

Private Elementary School

Public Elementary School

Private Middle School

Public Middle School

Home School

Other, please specify:

Where does child reside:

With me $100 \%$ of the time

With me $75 \%-99 \%$ of the time

With me $50 \%-74 \%$ of the time

With me $25 \%$ - $49 \%$ of the time

With me less than $25 \%$ of the time

If the child resides with you less than $100 \%$ of the time, who else does $\mathrm{s} /$ he life with?

\section{How many other children do you have?}

How many other children reside with the child you are reporting about?

Does your child have any serious medical problems/health issues?

Yes

No

If yes, please specify:

Has your child been diagnosed with autism spectrum disorder?

Yes

No 
If yes, please indicate age at diagnosis

Has your child been diagnosed with another disability?

Yes

No

If yes, please specify:

Has your child been diagnosed with a developmental delay?

Yes

No

If yes, please specify:

Please specify any disability related services your child is currently receiving. Note: You may mark as many as applicable

Speech/language Therapy

Hearing Services

Vision Services

Occupational Therapy

Physical Therapy

Behavioral Interventions (e.g., Applied Behavior Analysis)

Sensory Integration Therapy

Other

If other, please specify: 
Appendix B

Interview Questions

Can you tell me about your child?

What are some of your goals for your child?

Probe: What kind of hopes do you have for your child in the next 5 or 10 years?

Probe: What about social goals?

What do you see as your child's social strengths?

Probe: Can you give me an example?

Think about the last time you took your child to the grocery store. Can you tell me about it? What challenges come up? What does a successful trip to the grocery store with your child look like?

Tell me about your child's emotional needs?

Probe: How does your child express emotions (sadness, anger, fear)? Do you think they are able to understand their own emotions and the emotions of others?

Can you tell me about your experiences with early intervention?

Can you tell me a little bit about your feelings on intervention home-visits?

Can you tell me about a home visit that went really well?

Can you tell me about a home visit that was not as successful?

Probe: What would you have liked to have seen in this home visit?

Probe: What about in relation to the social and emotional goals we were talking about before?

When your child first began early intervention, what was the process like for planning the goals and services?

Probe: Were your goals for your child taken into account in the plan?

How would you describe your involvement during this process?

Probe: How did you involve yourself?

Probe: How did the provider involve you?

Probe: Was it easy for you to be as involved as you wanted to be?

Probe: What supports may have helped you be more involved?

Thinking about the overall experiences of your child and your family, what aspects of early intervention did you like?

Probe: Can you tell me a little more about this? 
What aspects of early intervention did you not like?

Probe: Can you tell me a little more about this?

What is the biggest thing your child and your family got from being involved in early intervention?

Is there anything else you would like me to know about your experiences with early intervention?

Can you describe your experience accessing services after aging out of early intervention? 
Appendix C

Description of Stage Model

\begin{tabular}{lll}
\hline Stage & Parent Perception & Themes \\
\hline Before Early & Frustration with initial & Frustration with pediatricians not referring; \\
Intervention & referral & parental agency in starting EI \\
During Early & Collaboration between & Family involvement and skilled service \\
Intervention & service providers and & providers; trust between service providers \\
& family members & and parents; child progress \\
After Early & Letdown after aging & Seeking private therapy; lag in services; \\
Intervention & out of EI & Reliance of self-education and parent \\
& & community to understand services available \\
& &
\end{tabular}




\section{Appendix D}

Frustration with the Initial Referral

\begin{tabular}{lll}
\hline \multicolumn{1}{c}{ Challenges } & \# of Parents & Definition \\
\hline Frustration with & $12 / 20$ & Parents expressed frustrations both that pediatricians \\
professionals for & did not refer their child for early intervention \\
not referring & services \\
Parental agency in & $12 / 20$ & After pediatricians did not refer, concerned parents \\
starting EI & & expressed taking the initiative to self-refer their \\
& & \\
&
\end{tabular}




\section{Appendix E}

Collaboration Between Service Providers and Family

\begin{tabular}{lll}
\hline Satisfaction Area & \# of Parents & Definition \\
\hline Family & $18 / 20$ & Parents expressed high satisfaction with their level \\
Involvement and & of involvement and providers who were skilled in \\
Skilled Providers & collaboration \\
Trust Between & $18 / 20$ & Parents expressed high levels of trust between \\
Providers and & & themselves and the providers \\
Parents & & As a result of high levels of collaboration with \\
Child Progress & $16 / 20$ & family and positive relationships with providers, \\
& & parents discussed high levels of child progress
\end{tabular}


Appendix F

Letdown After Early Intervention

\begin{tabular}{lll}
\hline \multicolumn{1}{c}{ Challenges } & \# of Parents & Definition \\
\hline Private Therapy & $7 / 20$ & Parents expressed frustration that because services \\
& were not provided in the public school setting, they \\
& had to seek private therapy for their child \\
Lag in Services & $13 / 20$ & Parents expressed frustration that as a result of a \\
& & lack of access to services, there was a lag between \\
Reliance on self- & $15 / 20$ & Parents relied on self-education and other parents to \\
education and & & \\
parent community &
\end{tabular}




\section{Appendix G}

Parent Goals

\begin{tabular}{lll}
\hline \multicolumn{1}{c}{ Stage } & \# of Parents & Definition \\
\hline Before EI & $10 / 20$ & Parents described goals for their children's \\
& development and described these goals as their \\
& rational for seeking EI services \\
During EI & Parents described their goals for their children \\
& during EI \\
After EI & Parents described their short- and long-term goals \\
& for their children after aging out of EI services at \\
& age 3 \\
\hline
\end{tabular}

